A. Kéromnès, W. K. Metcalfe, K. A. Heufer, N. Donohoe, A. K. Das, C. J. Sung, J. Herzler, C. Naumann, P. Griebel, O. Mathieu, M. C. Krejci, E. L. Petersen, W. J. Pitz, H. J. Curran, An Experimental and Detailed Chemical Kinetic Modeling Study of Hydrogen and Syngas Mixtures Oxidation at Elevated Pressures, Combustion and Flame 160 (2013) 995-1011.

The original publication is available at www.elsevier.com

http://dx.doi.org/10.1016/j.combustflame.2013.01.001 


\title{
An Experimental and Detailed Chemical Kinetic Modeling Study of Hydrogen and Syngas Mixtures Oxidation at Elevated Pressures
}

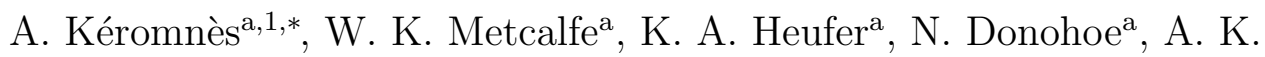 \\ Das $^{\text {b,c }}$, C. J. Sung ${ }^{\text {, }}$ J. Herzler ${ }^{\mathrm{d}}$, C. Naumann ${ }^{\mathrm{d}}$, P. Griebel ${ }^{\mathrm{d}}$, O. Mathieu ${ }^{\mathrm{e}}$, \\ M. C. Krejci ${ }^{\mathrm{e}}$, E. L. Petersen ${ }^{\mathrm{e}}$, W. J. Pitz ${ }^{\mathrm{f}}$, H. J. Curran ${ }^{\mathrm{a}, *}$ \\ ${ }^{a}$ Combustion Chemistry Centre, National University of Ireland, Galway, University Rd., \\ Galway, Ireland \\ ${ }^{b}$ Case Western Reserve University, Department of Mechanical \& Aerospace Engineering, \\ Cleveland, OH 44106 USA \\ ${ }^{c}$ University of Connecticut, Department of Mechanical Engineering, Storrs, CT 06269 \\ $U S A$ \\ ${ }^{d}$ German Aerospace Center (DLR), Institute of Combustion Technology, Stuttgart, \\ Germany \\ eTexas A \& M University, Department of Mechanical Engineering, College Station, TX \\ 77843 USA \\ ${ }^{f}$ Lawrence Livermore National Laboratory, Livermore, CA 94551 USA
}

\begin{abstract}
The oxidation of syngas mixtures was investigated experimentally and simulated with an updated chemical kinetic model. Ignition delay times for $\mathrm{H}_{2} / \mathrm{CO} / \mathrm{O}_{2} / \mathrm{N}_{2} /$ Ar mixtures have been measured using two rapid compression machines (RCM) and shock tubes at pressures from 1 to 70 bar, over a temperature range of $914-2220 \mathrm{~K}$ and at equivalence ratios from 0.1 to 4.0. Results show a strong dependence of ignition times on temperature and

\footnotetext{
${ }^{*}$ Corresponding authors

Email addresses: alan.keromnes@u-bourgogne.fr (A. Kéromnès), henry. curran@nuigalway.ie (H. J. Curran)

${ }^{1}$ Present address: Institut Supérieur de l'Automobile et des Transports (ISAT) DRIVE Laboratory, University of Burgundy, 49 rue Mlle Bourgeois, 58027 Nevers, France
} 
pressure at the end of the compression; ignition delays decrease with increasing temperature, pressure and equivalence ratio. The reactivity of the syngas mixtures was found to be governed by hydrogen chemistry for CO concentrations lower than $50 \%$ in the fuel mixture. For higher CO concentrations, an inhibiting effect of $\mathrm{CO}$ was observed. Flame speeds were measured in helium for syngas mixtures with a high $\mathrm{CO}$ content and at elevated pressures of 5 and 10 atm using the spherically expanding flame method.

A detailed chemical kinetic mechanism for hydrogen and $\mathrm{H}_{2} / \mathrm{CO}$ (syngas) mixtures has been updated rate constants have been and adjusted to reflect new experimental information obtained at high pressures, and new rate constant values recently published in the literature. Experimental results for ignition delay times and flame speeds have been compared to predictions using our newly revised chemical kinetic mechanism and good agreement was observed. In the mechanism validation, particular emphasis is placed on predicting experimental data at high pressures (up to 70 bar) and intermediateto high-temperature conditions: particularly important for applications in internal combustion engines and gas turbines. The reaction sequence $\mathrm{H}_{2}+$ $\mathrm{HO}_{2} \leftrightarrow \dot{\mathrm{H}}+\mathrm{H}_{2} \mathrm{O}_{2}$ followed by $\mathrm{H}_{2} \mathrm{O}_{2}(+\mathrm{M}) \leftrightarrow \dot{\mathrm{OH}}+\dot{\mathrm{OH}}(+\mathrm{M})$ was found to play a key role in hydrogen ignition under high-pressure and intermediatetemperature conditions. The rate constant for $\mathrm{H}_{2}+\mathrm{HO}_{2}$ showed strong sensitivity to high-pressure ignition times and has considerable uncertainty based on literature values. A rate constant for this reaction is recommended based on available literature values and on our mechanism validation.

Keywords: Hydrogen, Syngas, Kinetic mechanism, Rapid compression machine, shock tube, Ignition delay times, Flame speed 


\section{Introduction}

Hydrogen has attracted a lot of attention as a transportation fuel because of its low greenhouse gas emissions compared to carbon-based fuels. Although most current research is focused on using hydrogen in fuel cells, hydrogen can also be used with high efficiency in internal combustion (IC) engines to power transportation vehicles [1]. Hydrogen has drawn recent attention because, by using argon instead of nitrogen as a bath gas, higher efficiencies have been obtained in hydrogen engines [2, 3]. Syngas $\left(\mathrm{H}_{2}\right.$ and $\mathrm{CO}$ mixtures) has also been a focus of recent interest because it can be derived from the gasification of biomass and used for efficient power production in stationary gas turbines (GT) and engines. To design new engines, computational fluid dynamic (CFD) models are needed to simulate hydrogen and syngas combustion in IC engines and predict optimal engine design, operating conditions and performance. These CFD models need an accurate hydrogen/syngas chemical kinetic sub-model to predict the rate of reaction of this fuel under engine-relevant conditions. Many chemical kinetic models in the literature rely on detailed chemistry for hydrogen [3-9] and syngas [10-12]. However, fuel-air mixtures in an IC engine are subjected to higher pressures and temperatures than found in typical experimental setups for combustion studies. The syngas chemical kinetic mechanisms that are available in the literature have not been extensively validated at such high pressures and temperatures. Indeed, in 2006 Mittal et al. [13] stated that further refinements are still needed in the $\mathrm{H}_{2} / \mathrm{O}_{2}$ mechanism at high pressure and at intermediate temperatures to achieve good agreement with their ignition data from a rapid compression machine (RCM). 
There have been only a few experimental studies of hydrogen and syngas performed at high pressures and relatively low temperatures $(\leq 1000 \mathrm{~K})$. The hydrogen auto-ignition process was studied by Lee and Hochgreb [14] in an $\mathrm{RCM}$ over a pressure range of 6-40 bar, in the temperature range 950-1050 K using a stoichiometric mixture diluted in argon.

Recently, new experimental data has become available which extend the validation of hydrogen mechanisms to high pressures. Bradley et al. [15] and Burke et al. [16] have measured the laminar flame speed of hydrogen-air mixtures at elevated pressures up to 25 bar. Mittal and Sung [13] measured ignition delay times of hydrogen-air mixtures in a rapid compression machine at pressures up to 50 bar. Gersen et al. [17] studied the auto-ignition of hydrogen under conditions similar to those investigated by Lee and Hochgreb and Mittal et al. and found good agreement with the previous studies.

New experimental data has also become available to validate the syngas chemical kinetic mechanism. Mittal et al. [13] also used an RCM to measure ignition delays of syngas mixtures (from pure hydrogen to $80 \% \mathrm{CO}+20 \%$ $\mathrm{H}_{2}$ ) diluted mainly in argon over the same temperature range (950-1050 K) at end-of-compression pressures of 15, 30 and 50 bar. Their results agreed with the previous experiments of Lee and Hochgreb [14]. Walton et al. [18] studied the same type of mixture but used nitrogen as the diluent over a pressure and temperature range of 7.1-26.4 atm and 855-1051 K, respectively. Despite the experimental conditions being somewhat different, they found good agreement with previous studies.

In this study, new hydrogen and syngas oxidation data have been acquired. Ignition delay times have been measured in rapid compression ma- 
chines and shock tubes at pressures from 1 to 70 bar over a temperature range of 900-2500 $\mathrm{K}$ and at equivalence ratios from 0.1 to 4.0. The impact of the $\mathrm{CO}$ concentration on mixture oxidation behavior has been investigated for fuel mixtures over the range of pure hydrogen to fuel mixtures with $95 \%$ CO.

Flame speed measurements have been performed in helium for syngas mixtures with a high $\mathrm{CO}$ content $(95 \%)$ over an equivalence ratio range of 0.5-3.5 and pressures of 5 and 10 atm. Experimental results are finally compared to our newly revised chemical kinetic mechanism.

Using this experimental dataset extended to conditions of higher pressure and temperature, we have re-validated our chemical kinetic mechanism for $\mathrm{H}_{2}$ and $\mathrm{H}_{2} / \mathrm{CO}$ mixtures.

In the following sections, we describe the detailed chemical kinetic mechanism, present model validation comparisons and provide chemical kinetic insights into the behavior of hydrogen and syngas at pressures and temperatures characteristic of IC engines.

\section{Numerical model}

\subsection{Flame speed}

Chemkin Pro [20] was used to perform flame speed calculations. In preliminary flame calculations, we investigated the effect of the choice of Chemkin transport options on the computed flame speed. As a reference case, we used the Middha et al. [21, 22] baseline condition of a stoichiometric, hydrogen-air mixture at one atmosphere and an unburned gas temperature of $300 \mathrm{~K}$. The transport options tested included mixture averaged, multi- 
component and thermal diffusion options. The multicomponent transport model is more accurate than the mixture-averaged one. When thermal diffusion was included, the flame speed decreased by up to $8 \%$ for stoichiometric mixtures $(\phi=1.0)$ and $4 \%$ at $\phi=2.5$. This was the biggest effect found when selecting differences in the choice of transport options. For all of the flame speed results presented below, we used the multi-component and thermal diffusion options. Next, we investigated the number of grid points in the one-dimensional mesh needed for an accurate flame speed calculation. As the number of grid points was increased, the flame speed converged close to the value with 400 grid points. To be conservative, Chemkin convergence parameters were adjusted so that at least 800 grid points (and at times as many as 1000) were used in the calculations in this study.

\subsection{Rapid compression machine}

The ignition delay time calculations in a rapid compression machine use a volume profile generated from the corresponding non-reactive pressure trace for which an experiment is performed by replacing oxygen with nitrogen in the fuel/"air" charge. The volume history used for the simulation included the heat loss during the compression stroke by adding an empirically determined additional volume, and the heat loss after the end of compression was accounted for by the "adiabatic core expansion" approach [23]. The volume history is then used as an input in the Chemkin input file.

\subsection{Shock tube}

Shock tube data were simulated using constant volume, adiabatic conditions with the reflected shock pressure and temperature used as the initial 
conditions.

For long ignition delay times at lower temperatures in the DLR shocktube, a gas dynamic effect appears which slightly increases both the pressure and the temperature. The pressure and temperature variations due to the gas dynamics of the shock tube behind reflected shock waves are considered in the simulations by using MPFR (Multiple Plug Flow Reactor), an extension to CHEMKIN II [19]. This program, developed at DLR Stuttgart, takes into account gas dynamic effects causing pressure and temperature variations decoupled from the effects of heat release by chemical reactions combined with pressure relaxation effects along the shock propagation direction due to the shock tube's 'open end' configuration. Thus, the simulation assumes for a time period of typically $25 \mu$ s or shorter, depending on the temperature increase due to heat release $(\Delta T / T \leq 0.5 \%)$, a PFR with constant pressure conditions and takes into account the propagation of the pressure increase by heat release within a PFR time-step along the propagation direction of the reflected shock. The correction of the gas dynamic effects is based on measured pressure histories of mixtures with similar acoustic properties but without heat release by chemical reactions or of mixtures with very long ignition delay times and no heat release before ignition (see Fig. S1 in the Supplementary material). The temperature profiles are then calculated by applying adiabatic and isentropic conditions. These temperature profiles are used instead of constant initial temperatures $T_{5}$ for the simulation of the experiments. Thus, temperature variations are caused both, by the gas dynamics and the heat release of the reactive system. 


\subsection{Jet-stirred and variable-pressure-flow reactors}

Predicted species profiles have been compared to experimental species profiles from a jet-stirred reactor (JSR) and a variable-pressure flow reactor (VPFR). The JSR is simulated using the Aurora package in Chemkin Pro considering a constant volume, homogeneous, open reactor and assuming a constant temperature, pressure and residence time in the reactor. The convergence criterion is based on the change in species concentration. The VPFR is modeled using the Aurora package from Chemkin Pro assuming a constant pressure reactor. The initial conditions are defined by the initial experimental conditions. However, the model assumes a perfect and instantaneous mixing of the reactants which is not the case during the experiments. Therefore, the time at which reaction starts in the experiments is not welldefined and it is reasonable to shift the predicted species profiles relative to the measured profiles to account for nonidealities in reaction initiation. This profile is shifted in time such that the predicted point corresponding to $50 \%$ of the fuel disappearance matches that reported experimentally.

\section{Chemical kinetic mechanism}

Several reactions have been identified in the literature as being important for hydrogen and syngas oxidation. Previous studies of hydrogen $[4-6,10]$ have shown that its reactivity is mainly controlled by the competition between the chain-branching reaction:

$$
\dot{\mathrm{H}}+\mathrm{O}_{2} \leftrightarrow \ddot{\mathrm{O}}+\dot{\mathrm{O} H}
$$


and the pressure-dependent chain-propagating reaction

$$
\dot{\mathrm{H}}+\mathrm{O}_{2}(+\mathrm{M}) \leftrightarrow \dot{\mathrm{H}}_{2}(+\mathrm{M})
$$

Therefore, these two reactions have been studied extensively [24-29]. For high pressure conditions, the thermal decomposition of hydrogen peroxide $\left(\mathrm{H}_{2} \mathrm{O}_{2}\right)$ via the pressure-dependent reaction:

$$
\mathrm{H}_{2} \mathrm{O}_{2}(+\mathrm{M}) \leftrightarrow \dot{\mathrm{O}} \mathrm{H}+\dot{\mathrm{O}} \mathrm{H}(+\mathrm{M})
$$

becomes the dominant chain-branching reaction. Finally, as for most fuels, at intermediate temperatures, the reaction between the fuel and $\mathrm{H}_{2}$ :

$$
\mathrm{H}_{2}+\mathrm{HO}_{2} \leftrightarrow \mathrm{H}_{2} \mathrm{O}_{2}+\dot{\mathrm{H}}
$$

is important in the prediction of accurate ignition delay times.

Figure 1 shows the ignition behavior at low, intermediate and high temperature regions for 8,16 and 32 bar. The figure also gives reactions that control the ignition behavior in each temperature region. Under low- to intermediate-temperature conditions (in the temperature range investigated in RCMs), hydrogen oxidation is governed by $\mathrm{R} 9$ which leads to the production of $\mathrm{HO}_{2}$ radicals. The hydroperoxyl radical reacts with $\mathrm{H}_{2}$ leading to the formation of $\mathrm{H}_{2} \mathrm{O}_{2}$ which decomposes to two $\dot{\mathrm{O}} \mathrm{H}$ radicals. At higher temperatures (in the temperature range investigated in shock tubes), the competition between R1 and R9 leads to an unusual pressure dependence of the ignition delay times. Depending on the pressure, at higher temperatures the oxidation process is mainly governed by R1. Due to the pressure dependence of reaction $\mathrm{R} 9$, the temperature range at which the competition between R1 and R9 occurs depends on the pressure. 


\subsection{Sensitivity analysis}

In this section, a sensitivity analysis of the reaction mechanism is presented to show the important reactions that should be highlighted in the following discussion of the mechanism development. The sensitivity analysis has been performed with the present mechanism. The effect of the reaction rate constants on ignition delay times and flame speeds was examined. The analysis was performed over a wide range of pressure (1-100 bar) and temperature (850-1200 K) for ignition delay times (Figs. 2 and S2 in the Supplementary material). Each reaction is increased and decreased by a factor of two in calculating the ignition time. The sensitivity coefficient $(\sigma)$ is calculated by Equation 1 where $\tau^{\prime}$ and $\tau^{\prime \prime}$ are the calculated ignition times with the reaction increased and decreased, respectively. This analysis is performed assuming ideal (constant volume and adiabatic) conditions.

$$
\sigma=\frac{\log \left(\frac{\tau^{\prime}}{\tau^{\prime \prime}}\right)}{\log \left(\frac{2.0}{0.5}\right)}
$$

For the case of hydrogen, the sensitivity analysis shows that, at low temperature (below $1000 \mathrm{~K}$ ) and at relatively low pressure (1 atm), the reactivity is mainly controlled by the competition between the chain-branching reaction R1 and the chain-terminating reaction R9 (Fig. S2 in the Supplementary material). However, at higher temperatures ( $\mathrm{T} i, 1000 \mathrm{~K}$ ), the reactivity is only controlled by the chain-branching reaction. At high-pressure and intermediate-temperature conditions, Fig. 2, the reactivity is mainly controlled by the reactions producing and consuming $\mathrm{H}_{2} \mathrm{O}_{2}$, R15 and R17. This reaction sequence of fuel reacting with $\mathrm{HO}_{2}$ radicals to make $\mathrm{H}_{2} \mathrm{O}_{2}$ which subsequently decomposes to produce two $\dot{\mathrm{OH}}$ radicals leading to chain branching 
was first identified by Pitz and Westbrook [30]. These reactions are counterbalanced by the increasing sensitivity with pressure to the chain terminating reaction:

$$
\mathrm{HO}_{2}+\mathrm{HO}_{2} \leftrightarrow \mathrm{H}_{2} \mathrm{O}_{2}+\mathrm{O}_{2}
$$

The sensitivity analysis for flame speed was performed using Chemkin Pro. The sensitivity analysis is respect to mass flow rate which is directly proportional to flame speed. It was performed for hydrogen in air at room temperature and pressure and for a range of stoichiometries from 0.5 to 2.0 (Fig. 3). The flame speeds under these conditionsare controlled by the previously identified reactions R1 and R9 but other reactions also play a key role:

$$
\begin{gathered}
\ddot{\mathrm{O}}+\mathrm{H}_{2} \leftrightarrow \dot{\mathrm{H}}+\dot{\mathrm{OH}} \\
\dot{\mathrm{O}}+\mathrm{H}_{2} \leftrightarrow \dot{\mathrm{H}}+\mathrm{H}_{2} \mathrm{O} \\
\dot{\mathrm{HO}}_{2}+\dot{\mathrm{H}} \leftrightarrow \dot{\mathrm{O} H}+\dot{\mathrm{OH}} \\
\dot{\mathrm{HO}}_{2}+\dot{\mathrm{OH}} \leftrightarrow \mathrm{H}_{2} \mathrm{O}+\mathrm{O}_{2}
\end{gathered}
$$

It is evident that laminar flame speed is mainly controlled by the production and consumption of $\dot{H}$ atoms. The chain terminating reaction forming water via:

$$
\dot{\mathrm{H}}+\dot{\mathrm{O}} \mathrm{H}+\mathrm{M} \leftrightarrow \mathrm{H}_{2} \mathrm{O}+\mathrm{M}
$$

is also important, and increasing its rate constant reduces reactivity. Moreover, it has to be noted that R9 decreases flame reactivity under very lean conditions $(\phi \leq 0.7)$ but increases the reactivity of stoichiometric and rich 
mixtures. This is due to the competition between R11 and R13. Under lean conditions, there are fewer $\dot{\mathrm{H}}$ atoms available and the $\mathrm{HO}_{2}$ radical consumes the $\dot{\mathrm{OH}}$ radical to form water and molecular oxygen, whereas, under stoichiometric and rich conditions, the $\mathrm{H}_{2}$ radical can react with $\dot{\mathrm{H}}$ atoms to produce $\dot{\mathrm{OH}}$ radicals, R11. Therefore, we have paid particular attention to these reactions in updating the mechanism previously published by Ó Conaire et al. [4].

For the case of syngas, a sensitivity analysis was performed based on the mixture with the higher CO concentration tested by Mittal et al. [13] at three different end of compression pressures (15, 30 and 50 bar) at $1000 \mathrm{~K}$. Only the top fifteen most sensitive reactions have been plotted (Fig. 4). Only four reactions involving $\mathrm{CO}$ appear to be important in this system dominated by hydrogen chemistry:

$$
\begin{aligned}
\mathrm{CO}+\ddot{\mathrm{O}}+\mathrm{M} & \leftrightarrow \mathrm{CO}_{2}+\mathrm{M} \\
\mathrm{CO}+\mathrm{O}_{2} & \leftrightarrow \mathrm{CO}_{2}+\ddot{\mathrm{O}} \\
\mathrm{CO}+\dot{\mathrm{OH}} & \leftrightarrow \mathrm{CO}_{2}+\dot{\mathrm{H}} \\
\mathrm{CO}+\mathrm{HO}_{2} & \leftrightarrow \mathrm{CO}_{2}+\dot{\mathrm{OH}}
\end{aligned}
$$

Particular attention has been paid to these four reactions and these will be discussed below.

\subsection{Development of the hydrogen mechanism}

The detailed chemical kinetic mechanism of hydrogen is based on our earlier hydrogen mechanism [4]. Rate constants for reactions were updated to reflect more accurate values now available from measurements and calculations in the literature. The hydrogen experiments from Mittal et al. [13] 
were used as a benchmark in order to assess the performance of the hydrogen mechanism. The performance of the ignition delay time prediction is evaluated when it is updated with the recently published rate constant measurements. This evaluation has been performed through four main steps which are presented in Fig. 5. These steps are as follows. Fig. 5a presents the influence of the reaction rate for reactions $\mathrm{R} 1$ and $\mathrm{R} 17$. This results in the intermediate mechanism called "step 1". Fig. 5b presents the impact of the reaction rate for first pressure dependent reaction $\mathrm{R} 9$ and results in the second intermediate mechanism called "step 2". In Fig. 5c, the impact of two recent recommendations for the pressure dependent reaction R15 is assessed. Our recommendation results in the third intermediate mechanism called "step 3". Finally, Fig. 5d presents the performance of the present mechanism against the experimental results from Mittal et al. [13]. For the ignition calculations in a rapid compression machine, a special subroutine was used from Case Western Reserve University (CWRU) to simulate the volume history and heat losses in the machine.

The reactions and associated rate constants for the $\mathrm{H}_{2} / \mathrm{CO}$ mechanism are provided in Tables 1 and 2. The thermodynamic values used for species are given in the Supplementary material (Table S1). The enthalpy of formation of $\dot{\mathrm{OH}}$ radical is from the recent work of Ruscic et al. [31]. The enthalpy of formation for $\mathrm{HO}_{2}(2.94 \mathrm{kcal} / \mathrm{mole})$ is from Burcat's and Ruscic's database [32].

\subsection{1. $\dot{H}+O_{2} \leftrightarrow \ddot{O}+\dot{O} H(R 1)$}

The reaction $\mathrm{R} 1$ is not only extremely important in the hydrogen submechanism (Figs. 2, 3 and S2) but also dominates/controls the oxidation of 
all fuels undergoing oxidation at high temperature $(\mathrm{T} \geq 1000 \mathrm{~K}$ depending on the pressure). At temperatures below approximately $1000 \mathrm{~K}$, this reaction competes with the propagation reaction $\mathrm{R} 9$ which is inhibiting as it produces only one radical and not two reactive radicals as in the chain branching reaction. We have adopted the recently measured rate constant for $\mathrm{R} 1$ from Hong et al. [25]. They measured $\mathrm{H}_{2} \mathrm{O}$ absorption behind reflected shock wave at 2 atm over a tempereture range of 1100-1530 K. They combined their results with those previously reported by Masten et al. [29] over a temperature range of $1450-3370 \mathrm{~K}$ and found a very good agreement in the overlapping temperature range. Based on these two datasets, a rate constant was determined over a temperature range of 1100-3370 K with a reduced uncertainty of less than $10 \%$ over this temperature range. The rate constant is also in good agreement with the experimental results from Pirraglia et al. [33] and is used in recently published hydrogen mechanisms [6, 9].

This value is lower than our previous recommendation taken from the work of Hessler [34] and results in the prediction of slightly longer ignition times at intermediate temperatures and low pressures and slightly shorter ignition delay times at higher pressures (Fig. 5a).

\subsection{2. $\mathrm{H}_{2}+\mathrm{HO}_{2} \leftrightarrow \mathrm{H}_{2} \mathrm{O}_{2}+\dot{H}(R 17)$}

This reaction was found to exhibit a high sensitivity at the high pressures and low temperatures found in the RCM experiments (Fig. 2). At $1000 \mathrm{~K}$, the recommended rate constant from Baulch et al. [35] is a factor of three lower than Tsang and Hampson's recommendation [36]. A comparison of the different rate constants is given in the Supplementary material (Fig. S3). Based on the sensitivity results, this would result in a factor of 
three difference in ignition delay time at $1000 \mathrm{~K}$ and 50 bar. Ellingson et al. [37] recently used ab initio methods to compute the rate constant. They used canonical variational transition state theory with multidimensional tunneling $(\mathrm{CVT} / \mathrm{SCT})$ for the reverse reaction which leads to $\mathrm{H}_{2}+\mathrm{HO}_{2}$ and $\mathrm{H}_{2} \mathrm{O}+\dot{\mathrm{O}} \mathrm{H}$. Their calculation is similar to Tsang's recommendation below $1000 \mathrm{~K}$ and results in ignition delay times predictions that are much more consistent with Mittal and Sung's measurements. However, the ab initio rate constant was too fast compared to experimental data from Baldwin et al. [38] and so Ellingson et al. adjusted the barrier height to the upper theoretical limit in order to reduce the rate constant and match Baldwin's experimental data. Unfortunately in the RCM experiments, this adjustment results in a decreased reactivity and the model reproduces the RCM ignition delay data more precisely (Fig. 5a) when using the unaltered theoretical rate constant. Therefore, the unaltered theoretical reaction rate constant calculated by Ellingson et al. [37] is used in the present study.

\subsubsection{Pressure dependent reactions (R9 and R15)}

The reactivity of hydrogen is highly sensitive to the pressure dependent reactions $\mathrm{R} 9$ and $\mathrm{R} 15$ in the low- to intermediate-temperature regime. At $1000 \mathrm{~K}$ and low- to intermediate-pressure (below $10 \mathrm{~atm}$ ), R9 controls the reactivity whereas, at higher pressures and over the same temperature range, the reactivity is mainly controlled by R15 (Fig. 2).

$$
\dot{H}+O_{2}(+M) \leftrightarrow H \dot{O}_{2}(+M)(R 9)
$$

This chain propagation reaction which competes with $\mathrm{R} 1$ controls the low-temperature reactivity and requires a pressure dependent rate constant 
expression. A new pressure and temperature dependent rate constant for this key reaction has been determined by Fernandes et al. [24] over a pressure range of 1.5-950 bar and in the temperature range 300-900 K. This rate constant is based on experimental measurements in a high-pressure flow cell. The pressure and temperature range of R9 was further extended using unimolecular rate theory. However, the low-pressure limit rate constant proposed by Fernandes et al. [24] for argon as a bath gas reduces the reactivity of the mixture and results in too long shock tube ignition delays in the temperature range $(1000-1200 \mathrm{~K})$. Bates et al. [26] studied this reaction experimentally in argon over a temperature range of 1020-1260 K and over a pressure range of 10-150 bar, whereas Fernandes et al. performed argon experiments at a lower temperature range of 300-900 K. Combining the low-pressure limit rate constant from Bates et al. with the high-pressure limit from Fernandes et al. results in the best agreement of our mechanism with both RCM and shock tube measurements (Fig. 5b). A comparison between the resulting "hybrid" expression and the experimental measurement on which the fits were based is presented in the Supplementary material and shows very good agreement (Fig. S4).

Recent flame speed measurements in helium as a bath gas from Burke et al. [16] show a strong pressure dependence of the mass burning rate. The low-pressure limit defined by Fernandes et al. [24] for a temperature range of $300-900 \mathrm{~K}$ results in an over-prediction of the burning rate at $(\mathrm{T} \geq 1500 \mathrm{~K})$ and does not accurately reproduce the negative dependence with increasing pressure. Michael et al. [39] studied this reaction in various bath gases near the low-pressure limit. Their work suggests that experiments performed in 
Ar have slightly higher rate constant than in He. However, interestingly, recently published mechanisms by Burke et al. [16] and Hong et al. [6] use, respectively, an efficiency and a low-pressure limit which is higher for He than Ar. In the present study, increasing the low-pressure limit by a factor of 1.5 results in a better agreement of mass burning rates.

$$
\mathrm{H}_{2} \mathrm{O}_{2}(+M) \leftrightarrow \dot{O} H+\dot{O} H(+M)(R 15)
$$

The second main pressure dependent reaction involves the dissociation of hydrogen peroxide to two hydroxyl radicals. Under high-pressure and low- to intermediate-temperature conditions, ignition delay times are highly sensitive to this chain branching reaction R15 (Fig. 2). Pressure dependent rate constant expressions for this reaction have recently been published by Hong et al. [40] and by Troe [41]. Hong et al. [40] performed a shock tube study at 1.8 atm, over a temperature range of 1020-1460 K and suggested a new low-pressure limit rate constant together with a high-pressure limit rate constant from Sellevåg et al. [6, 42]. Troe [41] reviewed the experimental data, performed a theoretical study and derived a pressure dependent rate constant expression. Both the Hong et al. and Troe rate constant expressions have been implemented separately in our current reaction mechanism and tested against the ignition delay times measured by Mittal et al. (Fig. 5c). Both expressions use a higher high-pressure limit than that employed in the Ó Conaire mechanism. Thus, the resulting rate constants present a steeper fall-off behaviour (see Fig. S5 in the Supplementary material) and their rate constants are slower at low pressure and faster at high pressure. This results in an increased pressure dependence of the system. Using the Hong et al. rate constant expressions [40] results in the prediction of accurate ignition 
delay times at 15 bar but predicts too high a reactivity at both 30 and 50 bar (Fig. 5c). Troe's study [41] covers a wider pressure and temperature range and the use of his recommended set of rates accurately predicts the pressure dependence of the system. In this case, ignition delay times are accurately predicted for all three pressures. Troe's set of rate constants has been adopted for R15 in association with the set of rate constants for R9 from Fernandes [24] and Bates [26] previously discussed in Section 3.2.3 (Fig. 5c).

$$
\text { 3.2.4. } \mathrm{H}_{2} \mathrm{O}_{2}+\dot{\mathrm{O} H} \leftrightarrow \mathrm{H}_{2} \mathrm{O}+\mathrm{HO}_{2}(\mathrm{R} 19)
$$

This reaction requires the sum of two rate constant expressions to accurately reproduce its temperature dependence. The sum of two rate expressions for $\mathrm{H}_{2} \mathrm{O}_{2}+\dot{\mathrm{O}} \mathrm{H}=\mathrm{H}_{2} \mathrm{O}+\mathrm{HO}_{2}$ published by Hong et al. [40] have been compared with the two previously recommended by Hippler and Troe [43]. These rate constant expressions have been tested by combination with and without the rate constant proposed for $\mathrm{H}_{2} \mathrm{O}_{2}$ decomposition by Hong et al. and by Troe. We observe a low sensitivity of the mechanism to these reactions for the conditions depicted in Figs. 2 and S2, and have adopted the recent sum of two rate constant expressions of Hong et al. [40].

$$
\text { 3.2.5. } \dot{H}+\dot{O} H+M \leftrightarrow H_{2} O+M(R 8)
$$

Flame speed calculations are very sensitive to this recombination reaction forming water. Increasing this reaction rate decreases reactivity. In our previous mechanism, we used the value reported by Tsang and Hampson [36], but had multiplied it by a factor of two. More recently, Srinivasan and Michael [44] performed a shock tube study of the thermal decomposition of water at high temperature (2196-2792 K) and low pressure (6 and 
11 Torr) using Kr as the bath gas. They defined a new rate constant with an evaluated accuracy of $\pm 18 \%$. However, this resulting rate constant is a factor of two lower than the rate constant we previously used resulting in an overestimation of flame speeds. Some scattering still exists for this reaction rate and Konnov [5] estimated the remaining uncertainty of this reaction rate to be a factor of two. Li et al. [7] also modified the rate constant recommended by Tsang and Hampson [36]. More recently, Sellevåg et al. [45] studied this reaction and recommended a new rate constant lower than previous recommendations. We have optimized our mechanism recommending a rate constant which is slightly lower than Li's recommendation and adopted the efficiencies recommended in the GRI mechanism [12] to get best agreement of our mechanism with flame speed data (see Fig. S6 in the Supplementary material).

\subsubsection{Other reactions}

$$
\mathrm{H}_{2}+\dot{\mathrm{O}} \mathrm{H} \leftrightarrow \dot{\mathrm{H}}+\mathrm{H}_{2} \mathrm{O}(\mathrm{R} 3)
$$

Similar to reaction R8 above, flame speed predictions are also very sensitive to this reaction under fuel-lean conditions. The rate constant previously used from Michael and Sutherland [46] has been replaced by using the very recent rate constant recommended by Lam et al. [47]. The rate constant was measured using UV laser absorption of $\dot{\mathrm{O} H}$ radicals behind reflected shock waves over a temperature range of $902-1518 \mathrm{~K}$ and a pressure range of 1.15$1.52 \mathrm{~atm}$. They observed a very small experimental scatter (less than 7\%) which results in a reduced uncertainty of $\pm 17 \%$. Their recommendation is consistent with the previous work from Michael and Sutherland [46] and Oldenborg et al. [48]. 
$\mathrm{HO}_{2}+\dot{\mathrm{O}} \mathrm{H} \leftrightarrow \mathrm{H}_{2} \mathrm{O}+\mathrm{O}_{2}$ (R13)

This chain termination reaction, which is highly sensitive for fuel-lean flames (Fig. 3), has been studied experimentally and theoretically by many authors [9, 49-53]. However, there is a large discrepancy in the reported rate constant at intermediate temperatures, it can be up to a factor of four at $1200 \mathrm{~K}$, due to an unusual temperature dependence of the rate constant which creates an important non-Arrhenius behavior. The reported rate constant measurements show a deep and narrow minimum around $1250 \mathrm{~K}$. This behavior led to some authors having up to five expressions in order to reproduce the temperature dependence. This reaction has very recently been investigated experimentally by Hong et al. [49]. Their results are in good agreement with an earlier study by Srinivasan et al. [50] and the authors concluded that there is only a weak temperature dependence and recommended the rate constant reported by Baulch et al. [52] who recommended the rate constant defined by Keyser et al. [51] (see Fig. S7 in the Supplementary material). However, they recommended that future work be carried out to measure this reaction rate in the intermediate temperature range (900$1200 \mathrm{~K}$ ) due to a lack of data. Finally, Burke et al. [9] recently reported on theoretical work from Harding and Klippenstein [53] which also suggests a weak temperature dependence. We adopted the rate constant defined by Keyser et al. [51] but have reduced it by $15 \%$ to improve model agreement.

$\mathrm{H}_{2}+\mathrm{H}_{2} \leftrightarrow \mathrm{H}_{2} \mathrm{O}_{2}+\mathrm{O}_{2}(\mathrm{R} 14)$

This reaction inhibits reactivity under low-temperature, high-pressure conditions. This is due to the competition with reaction $\mathrm{R} 17$. If $\mathrm{HO}_{2}$ reacts will $\mathrm{H}_{2}$, it produces one $\mathrm{H}_{2} \mathrm{O}_{2}$ which will decompose into two $\dot{\mathrm{O}} \mathrm{H}$ radicals. 
Thus, one $\mathrm{HO}_{2}$ radical leads to the production of two $\dot{\mathrm{O}} \mathrm{H}$ radicals. On the contrary, reaction R14 consumes two $\mathrm{HO}_{2}$ radicals and produces one $\mathrm{H}_{2} \mathrm{O}_{2}$, thus leading to two $\dot{\mathrm{OH}}$ radicals, whereas four $\dot{\mathrm{OH}}$ radicals could have been formed through the other pathway. Therefore, this reaction can be considered as inhibitive under these conditions. It requires the sum of two rate constants to accurately reproduce its temperature dependence. The previously used set of rate constants from Hippler et al. [54] has been slightly reduced (by 13\%).

$H_{2}+\mathrm{O}_{2} \leftrightarrow H \dot{O}_{2}+\dot{H}(R 10)$

The rate constant used in the mechanism from Conaire et al. was taken from Tsang and Hampson [36] and is a two-parameter Arrhenius fit. However, the use of this rate constant increased the initial reactivity in flow reactor simulations of the Mueller et al. [28] data and resulted in inaccurate predictions. Therefore, the more recent rate constant defined by Michael et al. [55] was chosen due to its more accurate, non-Arrhenius 3 parameter fit and its pre-exponential factor has been reduced by $30 \%$ in order to reduce the reactivity at low temperature and keep the same reactivity at high temperature.

\subsection{CO sub-mechanism}

The CO mechanism initially comes from one prepared by Ó Conaire [56] which is based on the mechanism from Mueller et al. [57] and has been updated with recently published rate constants. Based on the sensitivity analysis performed (Fig. 4), only four reactions involving $\mathrm{CO}$ appear to be 
important in this system dominated by hydrogen chemistry:

$$
\begin{aligned}
\mathrm{CO}+\ddot{\mathrm{O}}(+\mathrm{M}) & \leftrightarrow \mathrm{CO}_{2}(+\mathrm{M}) \\
\mathrm{CO}+\mathrm{O}_{2} & \leftrightarrow \mathrm{CO}_{2}+\ddot{\mathrm{O}} \\
\mathrm{CO}+\dot{\mathrm{OH}} & \leftrightarrow \mathrm{CO}_{2}+\dot{\mathrm{H}} \\
\mathrm{CO}+\mathrm{HO}_{2} & \leftrightarrow \mathrm{CO}_{2}+\dot{\mathrm{O} H}
\end{aligned}
$$

These four reactions are discussed below. Moreover, syngas oxidation does not show a great sensitivity to the HCO sub-mechanism. However, these reactions are important for flame speed predictions of larger hydrocarbons (as shown by Li et al. [10] in Figs. 12, 21, 26 of their work).

\subsection{1. $\mathrm{CO}+\ddot{O}+M \leftrightarrow \mathrm{CO}_{2}+M($ R20)}

Initially, this reaction was described with a Lindemann fall-off expression, adopting the low-pressure limit from Westmoreland et al. [58] and the highpressure limit from Troe [59]. However, this combination does not accurately reproduce the pressure dependence of rich, high CO content, syngas flames, such as those measured by Sun et al. [60] resulting in an over-estimation of the flame speed. Sun et al. [60] recommended the rate constant defined by Baldwin et al. [61] which increases the inhibiting effect of CO. However, adopting this rate constant results in an over-estimation of the ignition delay times measured at 70 bar in the rapid compression machine (Fig. 9) for high CO concentrations, not accurately capturing the inhibiting effect of $\mathrm{CO}$ addition. Moreover, the $\mathrm{CO}$ inhibiting impact on ignition delay times measured by Mittal et al. [13] is not well reproduced at both 15 and 30 bar. New flame speed measurements (Fig. 10) highlight the uncertainty, especially for rich mixtures, and suggest that further work may be needed at 
high pressure and at high CO concentrations. Most satisfactory agreement was obtained by adopting the Lindemann fall-off expression and third body efficiencies recommended by Davis et al. [8] but reduced by $13 \%$ and $25 \%$ for the low- and high-pressure limits, respectively.

\subsection{2. $\mathrm{CO}+\dot{\mathrm{O}} \mathrm{H} \leftrightarrow \mathrm{CO}_{2}+\mathrm{H}$ (R22)}

The rate constant used in our mechanism for the reaction between CO and $\dot{\mathrm{OH}}$ was initially taken from Li et al. [10]. As stated by Li et al., based on the work from Zhao et al. [62], the laminar flame speed prediction is highly sensitive to the reactions $\mathrm{CO}+\dot{\mathrm{O} H}=\mathrm{CO}_{2}+\dot{\mathrm{H}}$ and $\mathrm{H} \dot{\mathrm{CO}}+\mathrm{M}=\dot{\mathrm{H}}+$ $\mathrm{CO}+\mathrm{M}$. To obtain better agreement with flame speed measurements for syngas mixtures, the Zhao et al. single reaction rate constant for the former reaction was replaced by the set of two reactions proposed as a result of the theoretical study performed by Joshi and Wang [63].

\subsection{3. $\mathrm{CO}+\mathrm{HO}_{2} \leftrightarrow \mathrm{CO}_{2}+\dot{\mathrm{O} H}(\mathrm{R} 23)$}

This reaction is the most sensitive of the $\mathrm{CO}$ sub-system under the conditions investigated (Fig. 4). The rate constant used for this reaction was updated taking the rate constant recently published by You et al. [64]. According to many authors [65-67], this rate constant considerably improves the prediction of RCM results published by Mittal et al. [13].

\section{4. $\dot{O} H^{\star}$ sub-mechanism}

Most of the ignition delay times recorded in shock tubes are based on the measurement of the chemiluminescence of $\dot{\mathrm{O}} \mathrm{H}^{\star}$, either the onset of the emission [68], the maximum rate of increase of the emission [69] or the peak of the $\dot{\mathrm{O}} \mathrm{H}^{\star}$ emission [70]. Therefore, it is important to predict an accurate 
$\dot{\mathrm{O}} \mathrm{H}^{\star}$ emission profile. Kathrotia et al. [71] recently published a new submechanism for the $\dot{\mathrm{O}} \mathrm{H}^{\star}$ chemiluminescence based on a previous study by Tamura [72] and updated with a new rate constant for the formation of $\dot{\mathrm{O}} \mathrm{H}^{\star}$ via $\dot{\mathrm{O}}+\dot{\mathrm{H}}+\mathrm{M} \leftrightarrow \dot{\mathrm{O}} \mathrm{H}^{\star}+\mathrm{M}$ measured during shock tube experiments. The rate constant of this reaction has no effect on the timing of the $\dot{\mathrm{O}} \mathrm{H}^{\star}$ profile and hence the ignition delay times derived. Therefore, the results herein are not dependent on the rate constant of this $\dot{\mathrm{O}} \mathrm{H}^{\star}$ reaction (and hence the absolute value of $\mathrm{OH}^{*}$ concentration). This sub-mechanism has been added to the $\mathrm{H}_{2} / \mathrm{CO}$ mechanism to predict accurately the ignition delay times measured in shock tubes.

\section{Experimental facilities}

\subsection{Rapid Compression Machine}

\subsubsection{NUIG Combustion Chemistry Centre}

Experiments were conducted in the rapid compression machine facility at NUI Galway. The RCM is a horizontally-opposed twin-piston device which has been described previously [73, 74]. The symmetry of the device helps to reduce the aerodynamic effects inside the combustion chamber at the end of the compression process [75]. The piston heads have been designed to include a uniquely shaped crevice that captures the piston corner vortex, thereby maximizing the homogeneity of the temperature field at full compression. As a result, the aerodynamic effect is reduced in the combustion chamber and both the temperature field and the mixture composition are homogeneous at the end of the compression process.

The thermodynamic conditions reached after the adiabatic compression 
process are relevant to gas turbines conditions. Top dead centre (TDC) is reached after 16-17 $\mathrm{ms}$ and the pistons are held in place to ensure constant volume conditions. In this study, different end-of-compression conditions are achieved by adjusting the initial pressure and temperature. Fuel-oxidizer mixtures were prepared manometrically in stainless steel tanks using gases with a purity of $99.9 \%$ or higher. The gases were mixed with an electronic stirrer in the tank. The experimental conditions are presented in Table 3.

For each experiment, the pressure was measured with a pressure transducer (Kistler 603B). The position of both pistons were measured with a shaft encoder. Both measurements were recorded using a digital oscilloscope. From the pressure profile, the compression time and the ignition delay time were both extracted. The ignition delay time was defined as the time interval between the end of the compression process and the maximum rate of increase of the pressure.

For each experiment with a reactive mixture, an experiment with the corresponding non-reactive mixture was performed by replacing the oxygen with nitrogen in the test mixture. Because nitrogen and oxygen have similar thermodynamic properties, the recorded pressure profile presents the same pressure drop as the reactive profile as a result of very similar heat loss properties. The reason for recording a pressure profile for each experiment with a non-reacting mixture was to characterize real heat losses in the kinetic simulations by producing a volume profile, assuming adiabatic compression and expansion processes and frozen chemistry, and using this as input in Chemkin's Aurora [20].

The experimental end-of-compression temperature, $T_{c}$, was calculated us- 
ing the initial temperature, $T_{i}$, and pressure, $p_{i}$, and the end-of-compression pressure, $p_{c}$. Calculations assumed adiabatic compression and frozen chemistry. They were carried out using Gaseq [76] which considers the temperature and the mixture composition dependence of the heat capacity in Equation (2).

$$
\ln \left(\frac{p_{c}}{p_{i}}\right)=\int_{T_{i}}^{T_{c}} \frac{\gamma}{\gamma-1} \frac{d T}{T}
$$

\subsubsection{UCONN RCM facility}

The experimental setup consists of a newly built rapid compression machine, a flow control/supply system, and a mixing chamber. Both the rapid compression machine and the mixing chamber along with the manifolds have a provision for heating up to a maximum temperature of $420 \mathrm{~K}$. For the current study, in order to cover the target range of water addition, the whole experimental setup is heated to a temperature of $400 \mathrm{~K}$.

The new RCM is similar to the one built by Mittal [77], with capability enhancements for attaining higher compression pressures and a wider range of compression ratios. The general details of the predecessor can be found from [78] while the details of the new RCM setup can be found in [79]. The new RCM was tested for consistencies with the old RCM result for $\mathrm{H}_{2} / \mathrm{O}_{2}$ mixtures at various pre-heat temperatures [79].

The RCM consists of a reaction chamber in which the reactant gases are compressed by a creviced piston arrangement. The creviced piston as shown by Mittal and Sung [78] improves the temperature uniformity substantially. An arrangement of a high-pressure air tank and a pneumatic cylinder drives the creviced piston. The creviced piston is held in place by an arrangement of the pressurized hydraulic cylinder. A 5V square pulse generated from 
Labview starts the data acquisition and triggers the solenoid to release the pressure of the hydraulic chamber. This results in forward movement of the piston arrangement by the pneumatic system. Towards the end of the compression stroke, the piston is smoothly decelerated and finally stopped by the piston stopping groove. For the cases presented here, the compression time is less than $30 \mathrm{~ms}$.

The end of the reaction chamber is equipped with a pressure transducer for dynamic measurements and a thermocouple for initial temperature monitoring. The compression ratio of the rapid compression machine can be changed by changing the clearance and/or the stroke length. Split shims are used between the hydraulic cylinder and the reaction chamber to vary the clearance whereas the stroke can be adjusted by using spacers.

The mixing chamber consists of an airtight stainless steel tank, including a magnetic stirrer to aid uniform mixing of the constituents. The tank is provided with a rupture disc as a safety measure against accidental overpressure within the mixing tank. Gases are filled into the mixing chamber by the method of partial pressures to prepare the pre-mixtures before heating it up to the desired temperature.

High-purity $\mathrm{H}_{2}$ (99.999\%), CO (99.998\%), $\mathrm{N}_{2}(99.999 \%)$, and $\mathrm{O}_{2}(99.993$ \%) gases are used for this study. It is to be noted that the effect of $\mathrm{Fe}(\mathrm{CO})_{5}$ generally present as impurity in $\mathrm{CO}$ can be quite substantial on combustion $[65,80]$. The concentration of $\mathrm{Fe}(\mathrm{CO})_{5}$ can also increase due to prolonged storage in steel tanks $[81,82]$. To ascertain the initial presence of $\mathrm{Fe}(\mathrm{CO})_{5}$, a test certificate for the gas cylinder was obtained, which showed no presence of $\mathrm{Fe}(\mathrm{CO})_{5}$. In order to avoid the buildup of $\mathrm{Fe}(\mathrm{CO})_{5}$ with time due to storage, 
the high purity $\mathrm{CO}$ used in this study was obtained in an aluminum tank.

For a given mixture composition, the end-of-compression gas temperature at the end of compression, $T_{c}$, is varied by altering the compression ratio, whereas the desired pressure at the end of compression, $p_{c}$, is obtained by varying the initial pressure of the reactive mixture.

\subsection{Shock tube measurements}

\subsubsection{TAMU shock tube facility}

A stainless steel, single-diaphragm shock tube was used to measure ignition delay times $\left(\tau_{i g n}\right)$ behind reflected shock waves (RSW) for $\mathrm{H}_{2} / \mathrm{O}_{2}$ mixtures diluted in $98 \%$ Ar. The driven section is 15.24-cm i.d., 4.72-m long, and the driver section is 7.62-cm i.d., 2.46-m long. Shock wave speeds were measured using five PCB-P113A piezoelectric pressure transducers mounted flush with the inner surface. Post reflected-shock conditions were determined using the measured incident wave speed extrapolated to the endwall in conjunction with the one-dimensional shock relations. The test pressure was monitored using one PCB-134A located at the endwall and one Kistler 603B1 located at the sidewall, in the same plane as the sapphire window used for the optical diagnostic.

Prior to each experiment, the shock tube was cleaned and the driven section was evacuated to $2 \times 10^{-5}$ Torr or better using a roughing pump and a turbomolecular pump in order to avoid any contamination. Mixtures were prepared manometrically into a stainless steel mixing tank, all gases having purity of $99.999 \%$ or higher (The purity of CO was $99.9 \%$ ). More details concerning the description of the shock tube and on the experimental procedure are available in [83]. The conditions investigated during this study for the 
$\mathrm{H}_{2} / \mathrm{O}_{2} /$ Ar mixtures are summarized in Table 5 (Ignition delay time measurements along with corresponding conditions behind the RSW are provided as supplemental material) and conditions investigated for the $\mathrm{H}_{2} / \mathrm{CO} / \mathrm{O}_{2} / \mathrm{Ar}$ mixtures are available in Krejci et al.[83].

Ignition delay times were measured at the sidewall location using emission spectroscopy from the $A^{2} \Sigma^{+} \rightarrow X^{2} \Pi$ transition of the excited-state hydroxyl radical $\left(\dot{\mathrm{OH}}^{\star}\right)$ using an interference filter centered at $307 \pm 10 \mathrm{~nm}$ with a Hamamatsu 1P21 photomultiplier tube. The ignition delay time was defined as the time between the passage of the reflected shock wave and the intersection of lines drawn along the steepest rate-of-change of $\dot{O} H^{\star}$ de-excitation and a horizontal which defines the zero-concentration level, as documented in [83]. Uncertainties in $\tau_{i g n}$ are of two sources: the uncertainty in the determination of $T_{5}$ (proven to be maintained below $10 \mathrm{~K}$ with the method used [84]) and the uncertainty associated with the determination of the steepest rate of change from the $\dot{\mathrm{O}} \mathrm{H}^{\star}$ profile. The temperature determination is the most important one and can lead to a relatively significant uncertainty in $\tau_{\text {ign }}$ for the high-pressure conditions of this study. This is due to a slight boundary layer effect which results in an increase in the pressure signal never higher than $2 \% / \mathrm{ms}$. Also, the time used during this study is reduced to less than $2 \mathrm{~ms}$ (typically less than $1.5 \mathrm{~ms}$ ). Burke et al. [9], based on the study from Pang et al. [85] stated that the influence of $\mathrm{d} p / \mathrm{dt}$ on the ignition delay time is important for ignition delay times longer than 1-2 ms, results yielding the same value for $\mathrm{d} p / \mathrm{dt}=2.0$ and $6.5 \%$ below $2 \mathrm{~ms}$. Overall, the corresponding increase in temperature would be less than $10 \mathrm{~K}$ for the longest ignition delay times reported herein and can therefore be considered negligible (under the 
experimental unertainty due to the shock wave velocity determination and the ignition delay time determination). Overall, the total uncertainty on $\tau_{\text {ign }}$ reported in this study is less than $10 \%$.

\subsubsection{DLR shock tube facility}

The experiments were carried out in a high-pressure shock tube with an internal diameter of $9.82 \mathrm{~cm}$. It is divided by aluminium diaphragms into a driver section of $5.18 \mathrm{~m}$ and a driven section of $11.12 \mathrm{~m}$ in length. The driven section can be pumped down to pressures below $10^{-6}$ mbar by a turbomolecular pump. Gas mixtures were prepared manometrically in a stainless steel storage cylinder, which is evacuated using a separate turbomolecular pump to pressures below $10^{-6}$ mbar. High-purity $\mathrm{H}_{2}$ ( $\left.\geq 99.9999 \%\right)$, CO ( $\left.\geq 99.997 \%\right)$, $\mathrm{N}_{2}(\geq 99.999 \%), \operatorname{Ar}(\geq 99.9999 \%)$ and $\mathrm{O}_{2}(\geq 99.9999 \%)$ were used for this study. The shock speed was measured over three $20 \mathrm{~cm}$ intervals using four piezoelectric pressure gauges. The temperature and pressure behind the reflected shock wave were computed from the measured incident shock speed and the speed attenuation using a one-dimensional shock model. The estimated uncertainty in reflected shock temperatures is less than $\pm 10 \mathrm{~K}$ in the temperature range of our measurements. The ignition was observed by measuring pressure profiles with piezoelectric gauges (PCB 113A24 and Kistler) located at a distance of $1 \mathrm{~cm}$ from the end flange. The PCB gauge was

shielded by $1 \mathrm{~mm}$ polyimide to reduce heat transfer. Also, the $\dot{\mathrm{O}} \mathrm{H}^{\star}$ at 308 $\mathrm{nm}$ at the same position was selected by a narrow band pass filter (FWHM $=5 \mathrm{~nm}$ ) and measured with a photomultiplier. All ignition delay time values shown in these paper were determined by measuring the time difference between the initiation of the system by the reflected shock wave and the 
occurrence of the $\dot{\mathrm{O}} \mathrm{H}^{\star}$ maximum because this allows a good comparability to the simulations. The experimental setup allows measurements of ignition delay times for observation times up to $6.5 \mathrm{~ms}$ depending on the temperature. Such long ignition delay times are strongly influenced by the pressure increase due to gasdynamics effect. This is considered in the simulations as presented in Section 2.3. Other effects like "mild ignition" occuring not close to the end flange are avoided by the dilution of the reactions with Ar.

\subsection{Flame speed measurement: TAMU Spherical Bomb facility}

The experimental facility used in this study is an aerospace-grade aluminum, constant-volume, cylindrical bomb equipped with 12.7 -cm diameter fused quartz windows at each end providing optical access. More information about the facility and its construction are detailed in de Vries et al. [86] and Lowry et al. [87]. Mixtures were prepared directly in the vessel using the partial pressure method via 0-1000 Torr and 0-500 psi pressure transducers. All gases used in this study were an ultra-high purity grade $(\geq 99.9 \%$ for each primary gas). To reduce hydrodynamic instabilities at pressures above atmospheric, helium was used as the diluent with an oxidizer ratio of 1:7 $\mathrm{O}_{2}$ :He. Experiments with initial pressures of 1 atm were performed with standard air. The mixture was spark-ignited from a separate control room using a constant-current power supply, a $10-\mu \mathrm{F}$ capacitor, an automotive ignition coil, and a solenoid switch. The spark occurs at the center of the vessel where two, 0.9-mm Alloy X electrodes with sharpened tips are separated by a variable gap.

Flame speed experiments have been carried out at an initial temperature of $295.7 \pm 2.5 \mathrm{~K}$ with initial pressures of $1 \pm 6.610^{-5}$ atm (0.05 Torr ac- 
curacy), and 5 and $10 \pm 0.003 \mathrm{~atm}$ (0.05 PSI accuracy). The accuracies on the final mixture pressures are the same on every component of the mixture (0.05 Torr for the experiments at $1 \mathrm{~atm}$ and on $\mathrm{H}_{2}$ and $\mathrm{CO}$ for the higher pressures and 0.05 PSI for the other components for the experiments above atmospheric pressure).

Flame propagation is recorded for each experiment using a Z-type schlieren setup similar to that described by Settles [88]. Light from a mercury arc lamp is collimated using an f/8 parabolic mirror with a $15.2-\mathrm{cm}$ diameter and directed through the optical windows of the experimental vessel. A second parabolic mirror located on the other side of the vessel focuses the collimated beam into a high-speed camera, Photron FastCam SA1.1. Before the light enters the camera, a circular pinhole aperture was placed at the focal point to intensify the density gradients.

\section{Results and discussion}

The updated kinetic mechanism has been validated over a wide range of oxidation studies, including ignition delays measured in both shock tube and rapid compression machines, species concentration profiles measured in a flow reactor and jet-stirred reactors and laminar flame speeds. These studies cover a wide range of temperatures $800-2500 \mathrm{~K}$ and pressures $1-50 \mathrm{bar}$. The performance of the current mechanism is presented below against a selection of targets covering the full range of conditions. A comprehensive validation is available in the Supplementary material. Burke et al. [9] recently performed a complete comparison of the available literature hydrogen mechanisms. Therefore only a comparison of the different $\mathrm{H}_{2} / \mathrm{CO}$ mechanisms is 
provided in the Supplementary material. Moreover, a comparison between the present mechanism and previously published mechanisms against the new experimental data presented in this paper is available in the Supplementary material.

The performance of the new mechanism has also been compared to the new ignition delay times measured in rapid compression machines and shock tubes for mixtures from pure hydrogen to $5 \% \mathrm{H}_{2}+95 \% \mathrm{CO}$ over a temperature range of 900-1740 K and for end-of-compression pressure from 1 to 70 bar. The ignition of syngas mixtures, from pure hydrogen to a high concentration of $\mathrm{CO}$, has been studied in two different RCMs. The study in NUI Galway was performed for a lean mixture over a pressure range of 8-32 bar and the study in the University of Connecticut was performed at a higher pressure of 70 bar.

\subsection{NUIG RCM Measurements}

Ignition delay times were recently measured for various lean $(\phi=0.5)$ syngas mixtures in the rapid compression machine from the Combustion Chemistry Centre (Figs. 6-8 and S9-S11). Measurements were performed at 8 bar, 16 bar and 32 bar. The mixtures and experimental conditions are provided in Table 3. Over this temperature range, increasing pressure results in higher reactivity of the mixture and shorter ignition delay times. However, for the highest temperatures, a cross over start to be observed due to the competition between R1 and R9. Increasing the amount of $\mathrm{CO}$ in the fuel mixtures results in longer ignition delay times showing the inhibiting effect of carbon monoxide on the hydrogen chemistry. The kinetic mechanism has been used to simulate these experimental results. The predicted ignition 
delay times are in very good agreement with experimental results. Both the inhibiting effect of $\mathrm{CO}$ and the unusual pressure dependence are well reproduced.

\subsection{UCONN RCM Measurements}

Ignition delay times for various syngas mixtures were measured in the rapid compression machine from the University of Connecticut. The study has been performed using stoichiometric conditions with 100\%, 50\%, 25\% and $10 \% \mathrm{H}_{2}$ in the $\mathrm{H}_{2} / \mathrm{CO}$ fuel mixtures with nitrogen dilution at an end-ofcompression pressure of 70 bar and an end-of-compression temperature range of 914-1068 K (Fig. 9). The mixture compositions are defined in Table 4. Results show the inhibiting effect of carbon monoxide on the syngas ignition delay times which increase with increasing amounts of $\mathrm{CO}$ in the syngas mixture. However, as noted previously by Mittal et al. [13] and Kalitan et al. [68] at lower pressure, this effect is more significant for fuel mixtures with a CO concentration greater than $50 \%$. The experimental results have been compared to ignition delay time predictions from the present mechanism, Fig. 9. The model captures accurately this inhibiting effect and its predictions are in very good agreement with the experimental results.

\subsection{DLR Shock tube measurement}

Ignition delay times of hydrogen and hydrogen / carbon monoxide mixtures were determined at 1, 4 and 16 bar and at a dilution of 1:5 (dilution 1:5 means one part of a fuel / oxygen / inert gas mixture, defined by the equivalence ratio and a ratio of 21/79 for oxygen / inert gas, and four parts of the inert gas). The mixture compositions are provided in Table 6. Additional to 
the hydrogen measurements at equivalence ratios of $\phi=0.5$ and 1.0 [70], the ignition delay times of very lean $(\phi=0.1)$ and fuel rich mixtures $(\phi=4.0)$ and the influence of nitrogen at $\phi=0.5$ as inert gas were determined. Experiments with different ratios of $\mathrm{H}_{2} / \mathrm{CO}(50 \% / 50 \%, 5 \% / 95 \%)$ were performed to determine the influence of $\mathrm{CO}$ on the ignition of syngas. The ignition delay times of two $\mathrm{H}_{2} / \mathrm{CO} / \mathrm{N}_{2} / \operatorname{Ar}$ mixtures $\left(\mathrm{H}_{2} / \mathrm{CO}=85 \% / 15 \%\right.$ and $50 \% / 50 \%$, $50 \% \mathrm{~N}_{2}$ and $50 \%$ Ar) were also determined at 16 bar.

The results of measurements are shown in Figs. 11-15 (and S12-S14 in the Supplementary material) together with simulations.

The simulations agree very well with the measurements. The complex pressure and inert gas dependence of the hydrogen and syngas mixtures is very well predicted. Deviations between the experiments and the simulations of hydrogen and syngas ignition can only be observed for the longest ignition delay times. This is probably caused by small deviations of the assumed and the real temperature profiles which exhibit a very pronounced influence on the ignition delay times. For the $5 \% \mathrm{H}_{2} / 95 \% \mathrm{CO}$ mixture at $\phi=0.5$, Fig. 13, the simulations predict longer ignition delay times at high temperatures. This may be caused by problems of determining short ignition delay times due to the very broad $\dot{\mathrm{O}} \mathrm{H}^{\star}$ maximum, see discussion below.

Figure 16 shows a comparison of the measured ignition delay times of the syngas mixtures at about 4 bar and $\phi=1.0$ together with values for $\mathrm{H}_{2}$ at equivalence ratios $\phi=0.1$ and 1.0 [70]. It can be seen that the characteristics of both of the $\mathrm{H}_{2} / \mathrm{CO}$ mixtures and of $\mathrm{H}_{2}$ are similar. At higher temperatures a lower activation energy is observed followed by a very steep increase at about $1000 \mathrm{~K}$. The ignition behaviour is dominated by the hydrogen content 
of the mixtures. The addition of $50 \% \mathrm{CO}$ has only a small influence on the measured ignition delay times. The syngas mixture with $5 \% \mathrm{H}_{2} / 95 \% \mathrm{CO}$ shows much longer ignition delay times at higher temperatures compared to the other hydrogen containing mixtures and compared to a $\mathrm{H}_{2} / \mathrm{O}_{2} / \mathrm{Ar}$ mixture $(\phi=0.1)$ with a similar low hydrogen content. This can be explained by the shape of the pressure and $\dot{\mathrm{O}} \mathrm{H}^{\star}$ emission profiles, Fig. 17. The pressure profiles show only a slight increase of the signal for a long time and the $\dot{\mathrm{O}} \mathrm{H}^{\star}$ signal shows a very broad peak beginning with a steep increase, followed by a slower increase to a maximum. These characteristics are well reproduced by the simulations, Fig. 18, which represents simulations for the experiment in Figure 17 (full lines) and a $\mathrm{H}_{2} / \mathrm{O}_{2} / \mathrm{Ar}$ mixture with the same hydrogen content ( $\phi=0.5$, CO replaced by Ar, dashed lines) at $1240 \mathrm{~K}$ and 3.79 bar. It can be seen that the hydrogen consumption is fast causing a steep increase of the $\dot{\mathrm{OH}}^{\star}$ signal. The much slower $\mathrm{CO}$ consumption is initialized by the hydrogen reactions. The slow CO oxidation causes only a slow temperature increase so that the observed pressure increase is also slow. The $\dot{\mathrm{O}} \mathrm{H}^{\star}$ signal is slowly increasing to a maximum due to the production of $\dot{\mathrm{H}}$ and $\dot{\mathrm{O}}$ atoms by the reactions during the $\mathrm{CO}$ oxidation:

$$
\begin{gathered}
\mathrm{CO}+\dot{\mathrm{O} H} \leftrightarrow \mathrm{CO}_{2}+\dot{\mathrm{H}} \\
\dot{\mathrm{H}}+\mathrm{O}_{2} \leftrightarrow \ddot{\mathrm{O}}+\dot{\mathrm{O}} \mathrm{H} \\
\dot{\mathrm{H}}+\ddot{\mathrm{O}}+(\mathrm{M}) \leftrightarrow \dot{\mathrm{O}} \mathrm{H}^{\star}
\end{gathered}
$$

Comparing the concentration profiles of the hydrogen and the $\mathrm{CO} / \mathrm{H}_{2} /$ $\mathrm{O}_{2} /$ Ar mixtures it can be seen that hydrogen is consumed earlier for the $\mathrm{CO} / \mathrm{H}_{2}$ mixtures due to the reaction $\mathrm{CO}+\mathrm{HO}_{2} \leftrightarrow \mathrm{CO}_{2}+\dot{\mathrm{O}} \mathrm{H}$ (R23) 
which transforms a less reactive $\mathrm{HO}_{2}$ radical into a more reactive $\dot{\mathrm{O}} \mathrm{H}$ radical. The faster $\mathrm{H}_{2}$ consumption leads to an earlier onset of $\dot{\mathrm{OH}^{\star}}$ production. Nevertheless, the maximum of the $\dot{\mathrm{O}} \mathrm{H}^{\star}$ occurs at significantly longer times for the $\mathrm{H}_{2} / \mathrm{CO}$ mixtures compared to the pure $\mathrm{H}_{2}$ mixtures due to the slow oxidation of $\mathrm{CO}$. As we define the ignition delay time as the maximum of the $\dot{\mathrm{O}} \mathrm{H}^{\star}$ signal, significantly longer ignition delay values for the $5 \% \mathrm{H}_{2}$ / 95\% CO mixtures are observed compared to other hydrogen containing mixtures. Using definitions of the ignition delay times like "onset of the $\dot{\mathrm{O}} \mathrm{H}^{\star}$ emission" or "maximum heat release rate" ignition delay times of less than $50 \%$ of the measured ones would be determined. This problem of the strong dependence of the values of the ignition delay times on their definition is only observed under dilute conditions with high CO content. For the $50 \%$ $\mathrm{H}_{2} / 50 \%$ CO mixture (Fig. 19) or for undiluted conditions the heat release of the hydrogen oxidation and the radical concentrations are much higher leading to rapid $\mathrm{CO}$ oxidation. The consumption of $\mathrm{H}_{2}$ is also accelerated for undiluted conditions compared to the $\mathrm{H}_{2} / \mathrm{O}_{2} / \mathrm{Ar}$ mixture. For the $50 \%$ $\mathrm{H}_{2} / 50 \% \mathrm{CO}$ mixture the acceleration of the $\mathrm{H}_{2}$ ignition is very small. If the $5 \% \mathrm{H}_{2} / 95 \% \mathrm{CO}$ mixture is further diluted $(\phi=0.5$, dilution 1:10) the oxidation of $\mathrm{CO}$ becomes even slower causing a very broad $\dot{\mathrm{OH}^{\star}}$ emission signal with two separated maxima due to the fast oxidation of $\mathrm{H}_{2}$ and the slow oxidation of CO [89].

\subsection{TAMU Shock tube measurement}

Recently, the ignition of various $\mathrm{H}_{2} / \mathrm{CO} / \mathrm{O}_{2}$ mixtures (with $\mathrm{H}_{2} / \mathrm{CO}$ ratios of $80 / 20,50 / 50,40 / 60,20 / 80$, and 10/90) diluted in $98 \%$ Ar was studied between 960 and $2000 \mathrm{~K}$. The equivalence ratio was set to 0.5 and pressures 
ranged from 1.5 to $30 \mathrm{~atm}$ [83]. Overall, results showed that an increase in the CO concentration led to an increase in the ignition delay time. This increase in the ignition delay time was however more pronounced for mixtures containing more than $50 \% \mathrm{CO}$ as fuel and results for the $80 \% \mathrm{H}_{2} / 20 \% \mathrm{CO}$ mixture would not present any distinguishable difference from the $\mathrm{H}_{2} / \mathrm{O}_{2}$ results of the present study. For all the mixtures, a crossover in the ignition delay times is observed with increasing temperature. For all the mixtures, a crossover in the ignition delay times is observed with increasing temperature. As for the $\mathrm{H}_{2} / \mathrm{O}_{2}$ mixtures in this study and in [70], it is due to the competition between $\mathrm{R} 1$ and $\mathrm{R} 9$. This unusual behaviour indicates that hydrogen is still governing the reactivity of the $\mathrm{H}_{2} / \mathrm{CO}$ mixture (even though an increase in carbon monoxide causes the activation energy of the mixture to slightly decrease in [83]). All of these results have been successfully reproduced by the model, especially for pressures above 1.6 atm.

New shock tube measurements

The ignition delay times of $\mathrm{H}_{2} / \mathrm{O}_{2}$ mixtures diluted in $98 \%$ Ar were determined for three different equivalence ratios: $0.3,0.5$ and 1.0. As can be seen in Fig. S15, for a pressure of around 13 atm, the effect of the equivalence ratio on the ignition delay times is not very significant for $\mathrm{H}_{2} / \mathrm{O}_{2}$ mixtures under the conditions investigated and the experimental trends were well captured by the model. A similar result for the effect equivalence ratio was found for the other pressures investigated and in the study of Herzler and Naumann [70]. The pressure dependence on the ignition delay observed for the data from [70] between 1 and 16 bar was also observed with the new data of this study, between 1.6 and 30 atm. As can be seen in Fig. 20, 21, 22 
for equivalence ratios $0.3,0.5$ and 1.0, respectively, the pressure dependence of hydrogen ignition is well reproduced by the model for all cases and the explanations provided for the results in Fig. 1 also apply to this new set of data obtained at higher pressures. 


\section{Conclusions}

This study presents new oxidation data for hydrogen and syngas mixtures. Flame speed and ignition delay times were measured over a wide pressure and temperature range of 1-70 bar and 900-2500 K, respectively. Ignition delay times were measured in both rapid compression machines and shock tubes. These new experimental results were compared to an updated mechanism for hydrogen and syngas mixtures with recently published reaction rate constant expressions for several critical reactions. The updated mechanism and validated for different oxidation studies (ignition delay times, flame speed, species profiles) and for a wide range of pressure (1-70 bar), temperature (900-2500 K) and equivalence ratios (0.1-4.0). The mechanism accurately reproduces high pressure and intermediate to high temperature data relevant to gas turbine conditions and therefore are of high interest. Under these particular conditions, the oxidation pathway $\mathrm{H}_{2}+\mathrm{HO}_{2} \leftrightarrow \dot{\mathrm{H}}+\mathrm{H}_{2} \mathrm{O}_{2}$ followed by $\mathrm{H}_{2} \mathrm{O}_{2}(+\mathrm{M}) \leftrightarrow \dot{\mathrm{OH}}+\dot{\mathrm{O} H}(+\mathrm{M})$ was found to be most crucial for accurate ignition delay time prediction, whereas at low pressure (1 atm) and low temperature (below $1000 \mathrm{~K}$ ) the reactivity is mainly controlled by the competition between the chain-branching reaction $\dot{\mathrm{H}}+\mathrm{O}_{2} \leftrightarrow \ddot{\mathrm{O}}+\dot{\mathrm{O}} \mathrm{H}$ and the pressure-dependent chain-propagating reaction $\dot{\mathrm{H}}+\mathrm{O}_{2}(+\mathrm{M}) \leftrightarrow \mathrm{HO}_{2}$ $(+M)$. This reaction was found to inhibit the reactivity of flame speed under very lean conditions and promotes the reactivity under stoichiometric to rich conditions. This behavior is explained by the production of $\mathrm{HO}_{2}$ radical which consumes or produces $\dot{\mathrm{OH}}$ radicals.

Syngas chemistry is governed by the hydrogen chemistry, and CO addition has an inhibiting effect. This effect is noticeable for $\mathrm{CO}$ concentrations of 
$50 \%$ or higher for ignition delay times measurement but appears for lower CO concentration for flame speed measurements. A CO concentration of $50 \%$ in the fuel results in an increase by a factor of two in the ignition delay times whereas a concentration of $90 \%$ increases the ignition delay times by a factor of ten. For flame speed, the same concentrations result in a reduction of flame speed by $35 \%$ and a factor of four respectively. Therefore, the inhibiting effect appears stronger for ignition delay times than for flame speeds, but is only significant for high CO concentrations. New flame speed measurements for syngas mixtures with a high $\mathrm{CO}$ concentration at 5 and $10 \mathrm{~atm}$ highlighted the remaining uncertainties for rich mixtures. Thus, further work is needed in order to reduce these uncertainties.

A comparison between the present mechanism and previously published mechanisms is provided in the Supplementary material. Overall, the predictions of the mechanisms for a series of fundamental shock tube, RCM, and flame speed experiments are in good agreement and the predictions are also in good agreement with the associated experimental data. However, some differences appear especially on the inhibiting effect of CO. The main differences appear at low to intermediate temperature due to the importance of the oxidation pathway through reactions $\mathrm{R} 9, \mathrm{R} 15$ and $\mathrm{R} 17$. It is crucial to correctly predict this oxidation pathway in order to correctly reproduce experimental results and many mechanisms fail. At higher temperature, under shock tube conditions, the reactivity is mainly controlled by reaction R1. The expressions for the rate constant used in the different mechanism are similar and this results in a very good agreement between the predictions and with the experimental data. 


\section{Acknowledgments}

The NUIG and DLR work is part of the European Project $\mathrm{H}_{2}$-IGCC funded by the European Commission and funding is gratefully acknowledged. Additional funding provided by Science Foundation Ireland and the Saudi Arabian Oil Company.

The LNLL work is performed under the auspices of the U.S. Department of Energy by Lawrence Livermore National Laboratory under Contract DEAC52-07NA27344.

The TAMU work is based upon the work supported by the Department of Energy under Award Number DE-FE0004679. Authors would like to thank C. J. Aul for his help in performing some of the shock-tube experiments; and A. Vissotski, D. Plichta, and S. Ravi for help on the flame speed experiments.

A.K.Das and C.J. Sung would like to acknowledge the support for their work at UConn from the Combustion Energy Frontier Research Center, an Energy Frontier Research Center funded by the U.S. Department of Energy, Office of Science, Office of Basic Energy Sciences under Award Number DESC0001198.

\section{References}

[1] C.M. White, R.R. Steeper, A.E. Lutz, Int. J. of Hydrogen Energy 31 (10) (2006) 1292-1305.

[2] R. Kuroki, A. Kato, E. Kamiyama, D. Sawada, SAE 2010-01-0581, 2010.

[3] N.J. Killingsworth, V.H. Rapp, D.L. Flowers, S.M. Aceves, J.Y. Chen, R. Dibble, Proc. Comb. Inst. 33 (2010) 3141-3149. 
[4] M. Ó Conaire, H.J. Curran, J.M. Simmie, W.J. Pitz, C.K. Westbrook, Int. J. Chem. Kinet. 36 (2004) 603-622.

[5] A.A. Konnov, Combust. Flame 152(4) (2008) 507-528.

[6] Z. Hong, D.F. Davidson, R.K. Hanson, Combust. Flame 158(4) (2011) 633-644.

[7] J. Li, Z.W. Zhao, A. Kazakov, F.L. Dryer, Int. J. Chem. Kinet. 36(10) (2004) 566-575.

[8] S.G. Davis, A.V. Joshi, H. Wang, F. Egolfopoulos, Proc. Combust. Inst. 30 (2005) 1283-1292.

[9] M.P. Burke, M. Chaos, Y. Ju, F.L. Dryer, S.J. Klippenstein, Int. J. Chem. Kinet. 44(7) (2012) 444-474.

[10] J. Li, Z.W. Zhao, A. Kazakov, M. Chaos, F.L. Dryer, J.J. Scire, Int. J. Chem. Kinet. 39(3) (2007) 109-136.

[11] H. Wang, X. You, A.V. Joshi, S.G. Davis, A. Laskin, F. Egolfopoulos, C.K. Law, USC Mech. Version II http://ignis.usc.edu/USC_Mech_II.htm, 2007.

[12] G.P. Smith, D.M. Golden, M. Frenklach, N.W. Moriarty, B. Eiteneer, M. Goldenberg, C.T. Bowman, R.K. Hanson, S. Song, J. William C. Gardiner, V.V. Lissianski, Z. Qin, "GRI-Mech VERSION 3.0," http://www.me.berkeley.edu/gri_mech/, 1999.

[13] G. Mittal, C.J. Sung, R.A. Yetter, Int. J. Chem. Kinet. 38(8) (2006) $516-529$. 
[14] D. Lee, S. Hochgreb, Int. J. Chem. Kinet. 30(6) (1998) 385-406.

[15] D. Bradley, M. Lawes, K. Liu, S. Verhelst, R. Woolley, Combust. Flame 149(1-2) (2007) 162-172.

[16] M.P. Burke, M. Chaos, F.L. Dryer, Y. Ju, Combust. Flame 157(4) (2010) 618-631.

[17] S. Gersen, N.B. Anikin, A.V. Mokhov, H.B. Levinsky, Int. J. Hydrogen Energy 33(7) (2008) 1957-1964.

[18] S.M. Walton, X. He, B.T. Zigler, M.S. Wooldridge, Proc. Combust. Inst. 31 (2007) 3147-3154.

[19] R. J. Kee, F. M. Rupley, J. A. Miller, Chemkin-II: A Fortran chemical kinetics package for the analysis of gas-phase chemical kinetics, Report No. SAND89-8009, Sandia National Laboratories, 1989.

[20] R.J. Kee, F.M. Rupley, J.A. Miller, M.E. Coltrin, J.F. Grcar, E. Meeks, H.K. Moffat, A.E. Lutz, G. Dixon-Lewis, M.D. Smooke, J. Warnatz, G.H. Evans, R.S. Larson, R.E. Mitchell, L.R. Petzold, W.C. Reynolds, M. Caracotsios, W.E. Stewart, P. Glarborg, C. Wang, C.L. McLellan, O. Adigun, W.G. Houf, C.P. Chou, S.F. Miller, P. Ho, P.D. Young, D.J. Young, D.W. Hodgson, M.V. Petrova, K.V. Puduppakkam, "CHEMKIN Release 4.1.1," Reaction Design, San Diego, CA, 2007.

[21] P. Middha, B. Yang, H. Wang, Proc. Combust. Inst. 29(1) (2002) 13611369. 
[22] P. Middha, H. Wang, Combust. Theory and Modelling 9(2) (2005) 353363.

[23] G. Mittal, C.J. Sung, "Rapid Compression Machine (RCM) Database," http://www.mae.case.edu/facilities/cdl/projects /rapidcomp/rapiddatabase/h2co, 2009.

[24] R.X. Fernandes, K. Luther, J. Troe, V.G. Ushakov, Phys. Chem. Chem. Phys. 10(29) (2008) 4313-4321.

[25] Z. Hong, D.F. Davidson, E.A. Barbour, R.K. Hanson, Proc. Combust. Inst. 33(1) (2011) 309-316.

[26] R.W. Bates, D.M. Golden, R.K. Hanson, C.T. Bowman, Phys. Chem. Chem. Phys. 3(12) (2001) 2337-2342.

[27] C.J. Cobos, H. Hippler, J. Troe, J. Phys. Chem. 89(2) (1985) 342-349.

[28] M.A. Mueller, R.A. Yetter, F.L. Dryer, Proc. Combust. Inst. 27(1) (1998) 177-184.

[29] D. A. Masten, R.K. Hanson, C.T. Bowman, J. Phys. Chem. 94(18) (1990) 7119-7128.

[30] W.J. Pitz, C.K. Westbrook, Combust. Flame 63 (1986) 113-133.

[31] B. Ruscic, A.F. Wagner, L.B. Harding, R.L. Asher, D. Feller, D.A. Dixon, K.A. Peterson, Y. Song, X.M. Qian, C.Y. Ng, J.B. Liu, W.W. Chen, J. Phys. Chem. A 106(11) (2002) 2727-2747. 
[32] A. Burcat and B. Ruscic, "Third Millennium Ideal Gas and Condensed Phase Thermochemical Database for Combustion," http://garfield.chem.elte.hu/Burcat/burcat.html, 2009.

[33] A.N. Pirraglia, J.V. Michael, J.W. Sutherland, R.B. Klemm, J. Phys. Chem. 93 (1989) 282291.

[34] J.P. Hessler, J. Phys. Chem. A 102(24) (1998) 4517-4526.

[35] D.L. Baulch, C.T. Bowman, C.J. Cobos, R.A. Cox, T. Just, J.A. Kerr, M.J. Pilling, D. Stocker, J. Troe, W. Tsang, R.W. Walker, J. Warnatz, J. Phys. Chem. Ref. Data 34(3) (2005) 757-1397.

[36] W. Tsang, R.F. Hampson, J. Phys. Chem. Ref. Data 15 (1986) 10871280.

[37] B.A. Ellingson, D.P. Theis, O. Tishchenko, J. Zheng, D.G. Truhlar, J. Phys. Chem. A 111(51) (2007) 13554-13566.

[38] R.R. Baldwin, D. Jackson, R.W. Walker, S.J. Webster, Trans. Faraday Society 63(535P) (1967) 1676.

[39] J.V. Michael, M.-C. Su, J.W. Sutherland, J.J. Carroll, A.F. Wagner, J. Phys. Chem. A 106(21) (2002) 5297-5313.

[40] Z.K. Hong, R.D. Cook, D.F. Davidson, R.K. Hanson, J. Phys. Chem. A 114(18) (2010) 5718-5727.

[41] J. Troe, Combust. Flame 158(4) (2011) 594-601. 
[42] S.R. Sellevåg; Y. Georgievskii, J.A. Miller, J. Phys. Chem. A 113(16) (2009) 4457-4467.

[43] H. Hippler, J. Troe, Chem. Phys. Lett. 192(4) (1992) 333-337.

[44] N.K. Srinivasan, J.V. Michael, Int. J. Chem. Kinet. 38(3) (2006) 211219.

[45] S.R. Sellevåg, Y. Georgievskii, J.A. Miller, J. Phys. Chem. A 112(23) (2008) 5085-5095.

[46] J. Michael, J.W. Sutherland, J. Phys. Chem 92 (1988) 2853-3857.

[47] K-Y.Lam, D.F. Davidson, R.K. Hanson, submitted to Int. J. Chem. Kinet. (2012)

[48] R.C. Oldenborg, G.W. Loge, D.M. Harradine, K.R. Winn, J. Phys. Chem. 96(21) (1992) 8426-8430.

[49] Z.K. Hong, S.S. Vasu, D.F. Davidson, R.K. Hanson, J. Phys. Chem. A 114(17) (2010) 5520-5525.

[50] N.K. Srinivasan, M.C. Su, J.W. Sutherland, J.V. Michael, B. Ruscic, J. Phys. Chem. A 110(21) (2006) 6602-6607.

[51] L.F. Keyser, J. Phys. Chem. 92 (1988) 1193-1200.

[52] D.L. Baulch, C.J. Cobos, R.A. Cox, C. Esser, P. Frank, T. Just, J.A. Kerr, M.J. Pilling, J. Troe, R.W. Walker; J. Warnatz, J. Phys. Chem. Ref. Data 21(3) (1992) 411-734.

[53] L.B. Harding, S.J. Klippenstein, private communication. 
[54] H. Hippler, J. Troe, J. Willner, J. Chem. Phys. 93(3) (1990) 1755-1760.

[55] J.V. Michael, J.W. Sutherland, L.B. Harding, A.F. Wagner, Proc. Combust. Inst. 28(2) (2000) 1471-1478.

[56] M. Ó Conaire, PhD Thesis, National University of Ireland Galway (2005).

[57] M.A. Mueller, R.A. Yetter, F.L. Dryer, Int. J. Chem. Kinet. 31(10) (1999) 705-724.

[58] P.R. Westmoreland, J.B. Howard, J.P. Longwell, A.M. Dean, AIChE Journal 32(12) (1986) 1971-1979.

[59] J. Troe, J. Phys. Chem. 83 (1979) 114-126.

[60] H. Sun, S.I. Yang, G. Jomaas, C.K. Law, Proc. Combust. Inst. 31(1) (2007) 439-446.

[61] R.R. Baldwin, D. Jackson, A. Melvin, B.N. Rossiter, Int. J. Chem. Kin. 4 (1972) 277-292.

[62] Z.W. Zhao, J. Li, A. Kazakov, F.L. Dryer, Int. J. Chem. Kinet. 37(5) (2005) 282-295.

[63] A.V. Joshi, H. Wang, Int. J. Chem. Kinet. 38(1) (2006) 57-73.

[64] X. You, H. Wang, E. Goos, C-J. Sung, S.J. Klippenstein, J. Phys. Chem. A 111(19) (2007) 4031-4042.

[65] M. Chaos, F.L. Dryer, Combust. Sci. Tech. 180(6) (2008) 1053-1096. 
[66] C-J. Sung, C.K. Law, Combust. Sci. Tech. 180(6) (2008) 1097-1116.

[67] C.L. Rasmussen, J. Hansen, P. Marshall, P. Glarborg, Int. J. Chem. Kinet. 40(8) (2008) 454-480.

[68] D.M. Kalitan, J.D. Mertens, M.W. Crofton, E.L. Petersen, J. Prop. Power 23(6) (2007) 1291-1303.

[69] K.A. Bhaskaran, M.C. Gupta, T. Just, Combust. Flame 21(1) (1973) $45-48$.

[70] J. Herzler, C. Naumann, Proc. Combust. Inst. 32(1) (2009) 213-220.

[71] T. Kathrotia, M. Fikri, M. Bozkurt, M. Hartmann, U. Riedel, C. Schulz, Combust. Flame 157(7) (2010) 1261-1273.

[72] M. Tamura, P.A. Berg, J.E. Harrington, J. Luque, J.B. Jeffries, G.P. Smith, D.R. Crosley, Combust. Flame 114(3-4) (1998) 502-514.

[73] L. Brett, J. MacNamara, P. Musch, J.M. Simmie, Comb. Flame 124(1-2) (2001) 326-329.

[74] S.M. Gallagher, H.J. Curran, W.K. Metcalfe, D. Healy, J.M. Simmie, G. Bourque, Combust. Flame 153(1-2) (2008) 316-333.

[75] J. Würmel, J. M. Simmie, Combust. Flame 141 (2005) 417-430.

[76] Morley, Gaseq ver 0.79 (2005) http://www.c.morley.dsl.pipex.com/.

[77] G. Mittal, PhD Thesis, Case Western Reserve University, (2006).

[78] G. Mittal, C-J. Sung, Combust. Sci. Tech. 179 (2007) 497-530. 
[79] A.K. Das, C.J. Sung, Yu Zhang, G. Mittal, Int. J. Hydrogen Energy 37 (2012) 6901-6911.

[80] V. Babushok, W. Tsanga, G.T. Linteris, D. Reinelt, Combust. Flame 115 (1998) 551-560.

[81] H.R. Ambler, T.C. Sutton, Analyst. (1934) 809-811.

[82] J. Sendroy Jr., H.A. Collison, H.J. Mark, Anal. Chem. 27 (1995) 16411645.

[83] M.C. Krejci, O. Mathieu, A.J. Vissotski, S. Ravi, T.G. Sikes, E.L. Petersen, A. Keromnes, W. Metcalfe, H.J. Curran Paper GT2012-69290, Proceedings of ASME Turbo Expo 2012-GT2012.

[84] E.L. Petersen, M.J.A. Rickard, M.W. Crofton, E.D. Abbey, M.J. Traum, D.M. Kalitan. Meas. Sci. Tech. 16 (2005) 1716-1729.

[85] G.A. Pang, D.F. Davidson, R.K. Hanson, Proc. Combust. Inst. 32 (2009) $181-188$.

[86] J. de Vries, W. Lowry, Z. Serinyel, H.J. Curran, E.L. Petersen, Fuel, 90(1) (2011) 331-338.

[87] W. Lowry, J. de Vries, M. Krejci, Z. Serinyel, W. Metcalfe, H.J. Curran, E.L. Petersen, G. Bourque, J. Eng. Gas Turbines and Power, 133(9) (2011) Article Number: 091501.

[88] G.S. Settles, Schlieren and Shadowgraph Techniques, Springer, Heidelberg, Germany, 2006. 
[89] J. Herzler, C. Naumann, Comb. Sci. Tech. 180 (2008) 2015-2028.

[90] J.W. Sutherland, J.V. Michael, A.N. Pirraglia, F.L. Nesbitt, R.B. Klemm, Proc. Combust. Inst. 21 (1986) 929-941.

[91] J.W. Sutherland, P.M. Patterson; R.B. Klemm, Proc. Combust. Inst. 23 (1991) 51-57.

[92] R.S. Timonen, E. Ratajczak, D. Gutman, J. Phys. Chem. 92(3) (1988) $651-655$.

[93] R.S. Timonen, E. Ratajczak, D. Gutman, J. Phys. Chem. 91(3) (1987) 692-694.

[94] P.H. Paul, J.L. Durant, J.A. Gray, M.R. Furlanetto, J. Chem. Phys. 102(21) (1995) 8378-8384.

[95] G.P. Smith, J. Luque, C. Park, J.B. Jeffries, D.R. Crosley, Combust. Flame 131(1-2) (2002) 59-69. 


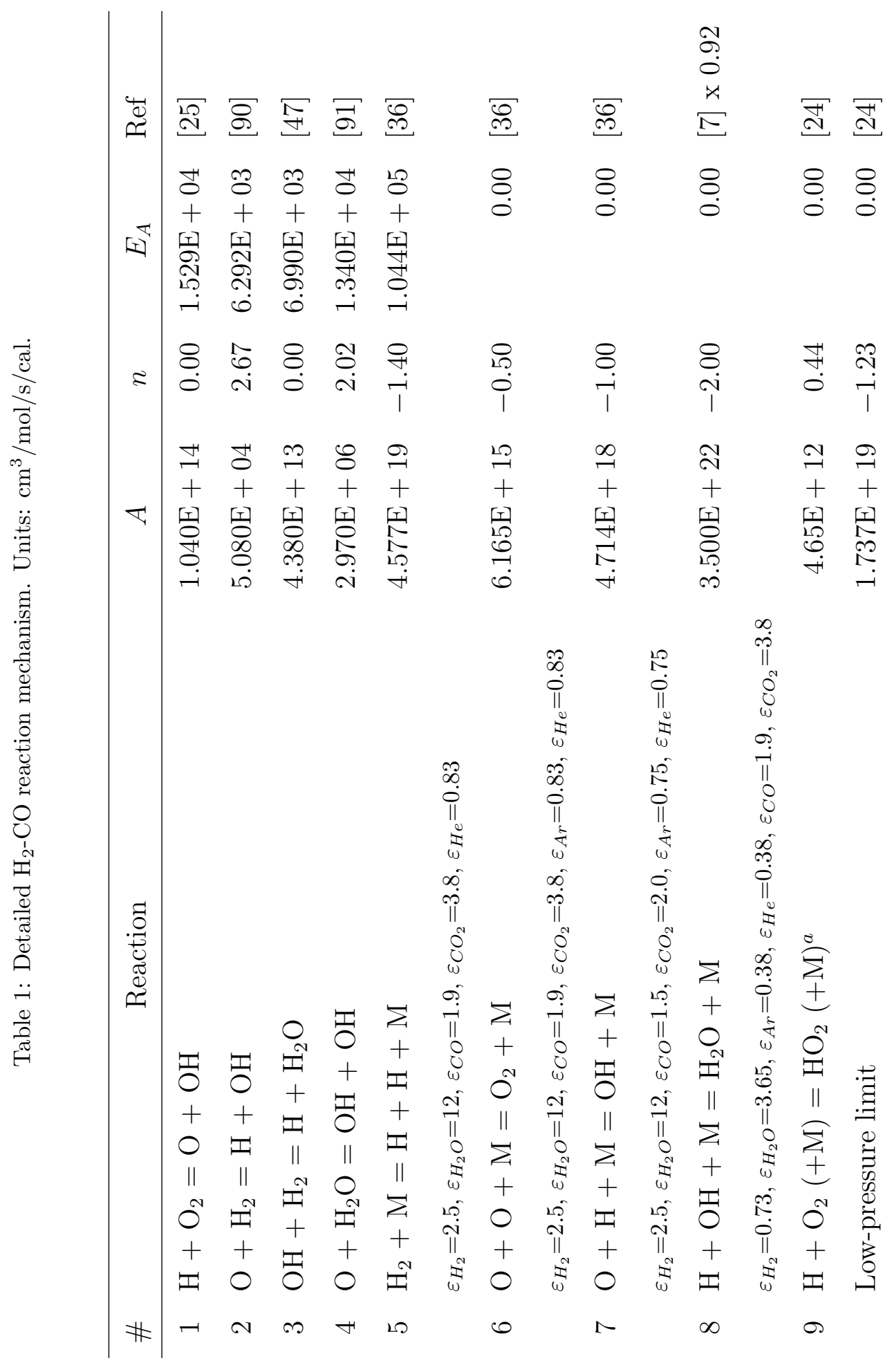




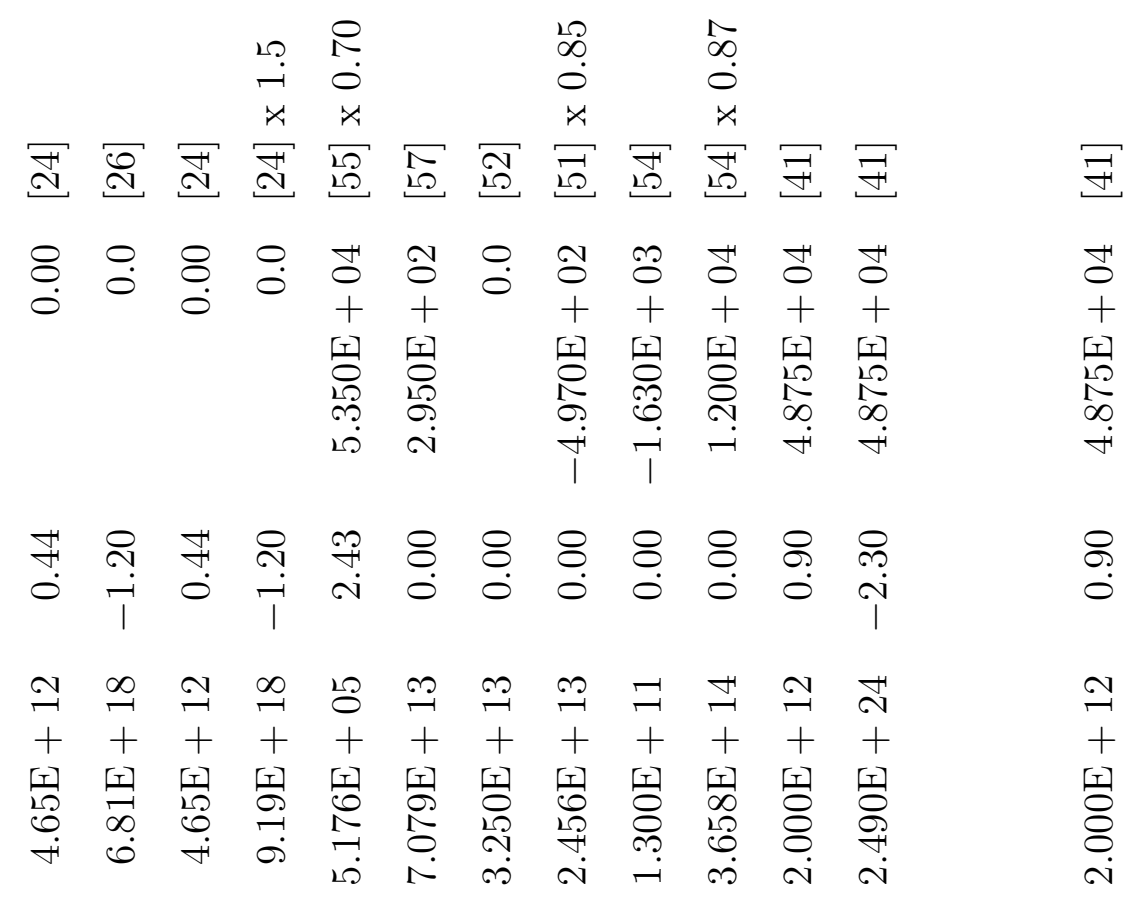

0
0
11
0
$\omega$
0
$\dot{0}$
11
$\dot{5}$
$\omega$
$\infty$
$\infty$
0
0

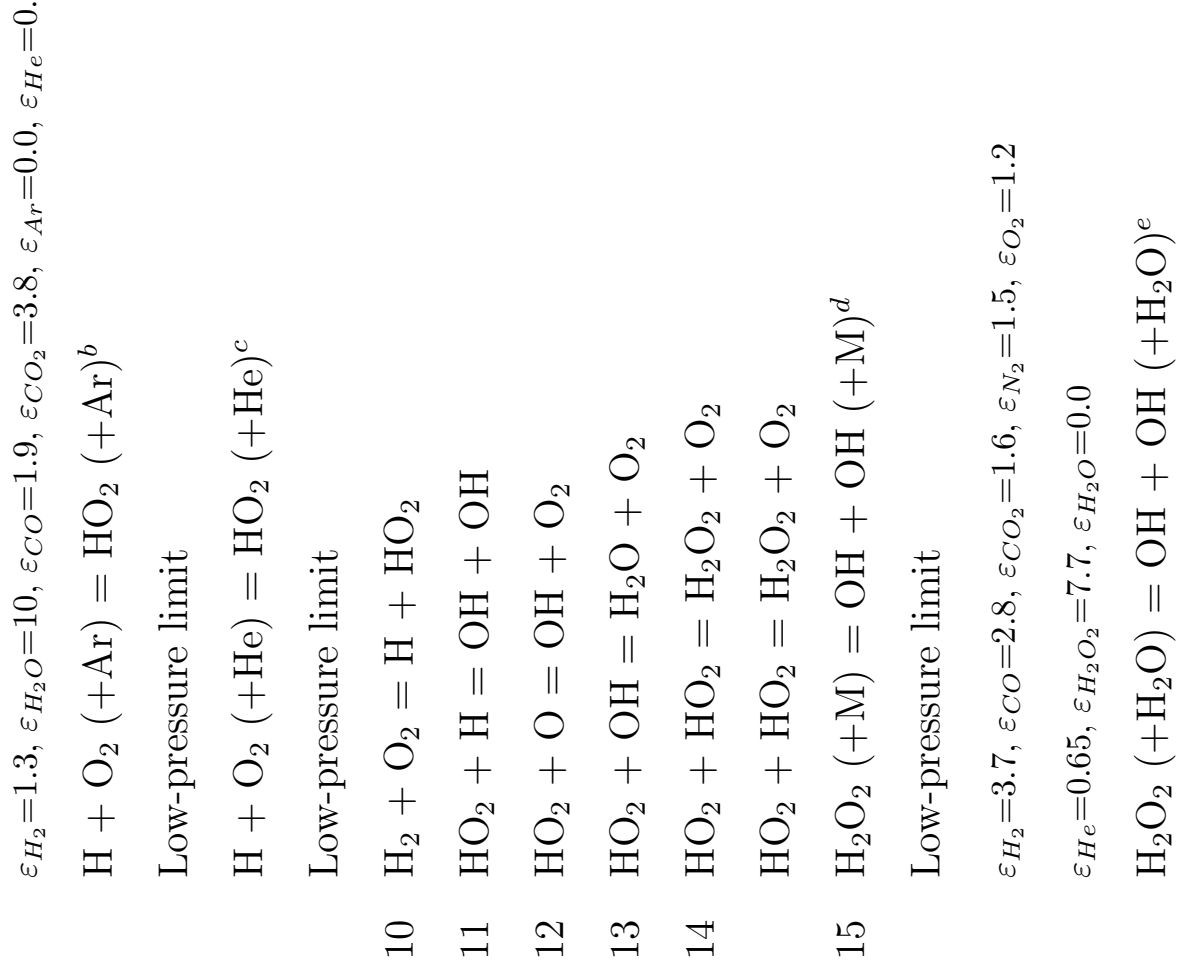




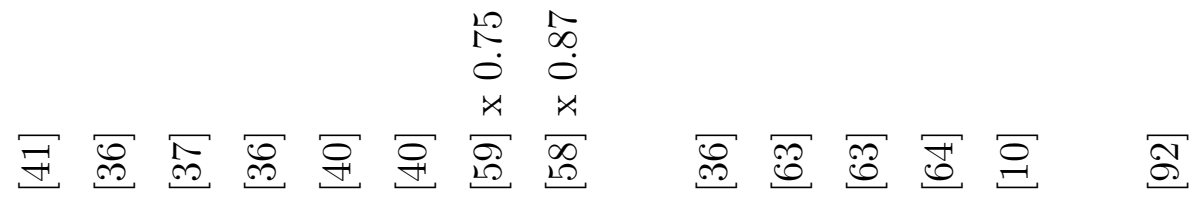

艹

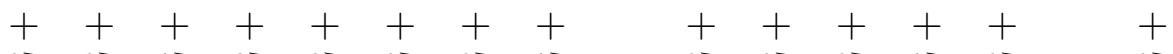

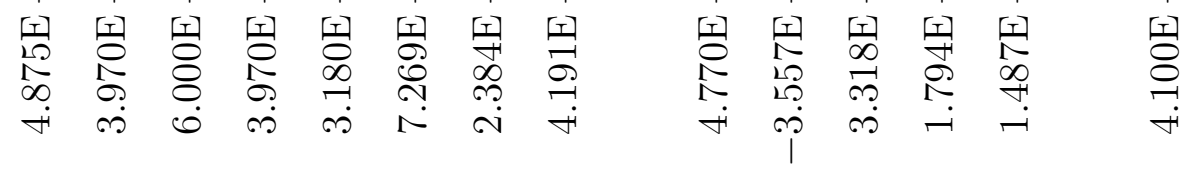

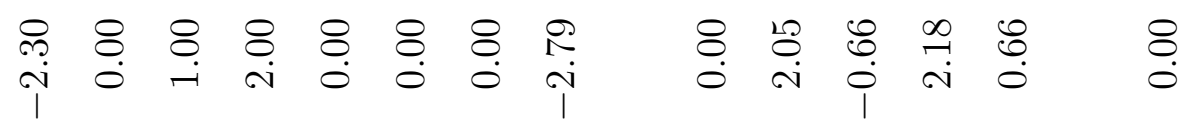

เ

$+++++++++++4$

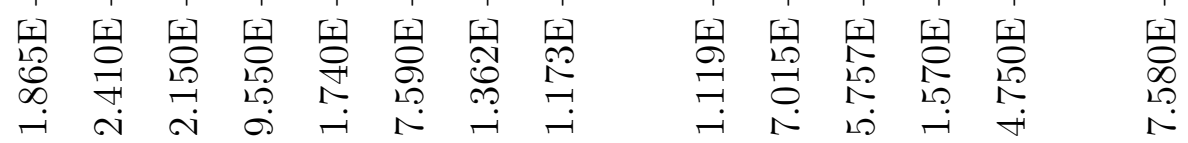

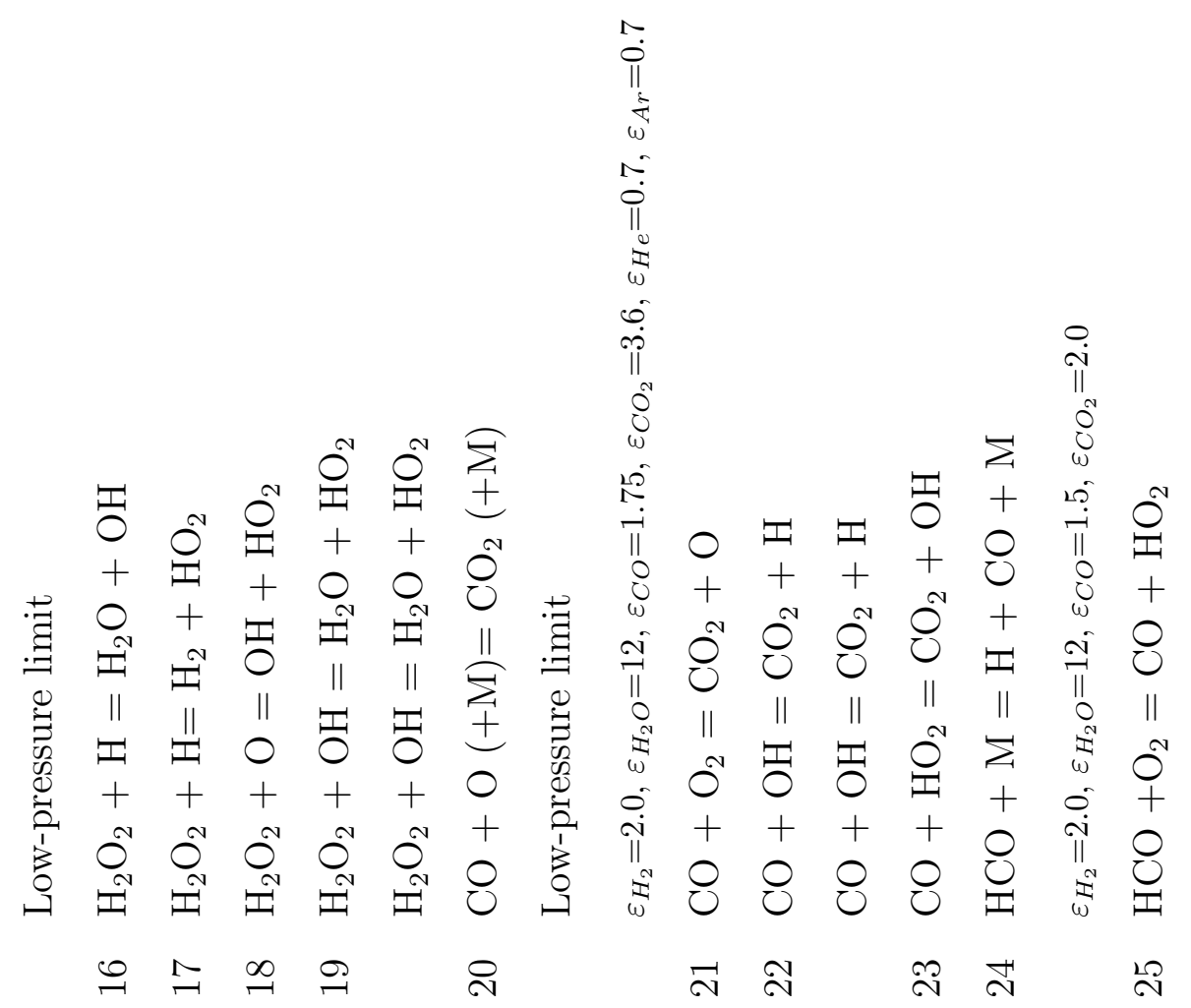




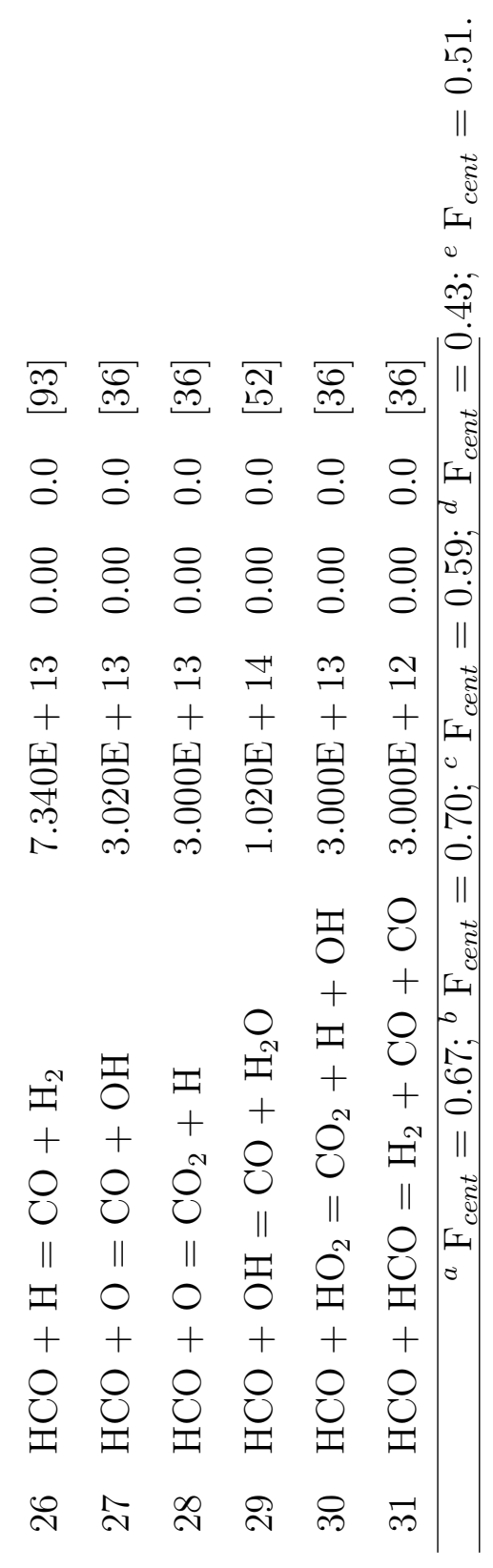


Table 2: $\dot{\mathrm{O}} \mathrm{H}^{\star}$ Chemiluminescence reaction mechanism. Units: $\mathrm{cm}^{3} / \mathrm{mol} / \mathrm{s} / \mathrm{cal}$.

\begin{tabular}{llccrr}
\hline$\#$ & \multicolumn{1}{c}{ Reaction } & $A$ & $n$ & $E_{A}$ & Ref \\
\hline 32 & $\mathrm{H}+\mathrm{O}+\mathrm{M}=\mathrm{OH}^{\star}+\mathrm{M}$ & $1.500 \mathrm{E}+13$ & 0.00 & $5.975 \mathrm{E}+03$ & {$[71]$} \\
& $\varepsilon_{H_{2} O}=6.5, \varepsilon_{O_{2}}=0.4, \varepsilon_{N_{2}}=0.4, \varepsilon_{A r}=0.35$ & & & & \\
33 & $\mathrm{OH}^{\star}+\mathrm{O}_{2}=\mathrm{OH}+\mathrm{O}_{2}$ & $2.100 \mathrm{E}+12$ & 0.50 & $-4.820 \mathrm{E}+02$ & {$[72]$} \\
34 & $\mathrm{OH}^{\star}+\mathrm{H}_{2}=\mathrm{OH}+\mathrm{H}_{2}$ & $2.950 \mathrm{E}+12$ & 0.50 & $-4.440 \mathrm{E}+02$ & {$[72]$} \\
35 & $\mathrm{OH}^{\star}+\mathrm{N}_{2}=\mathrm{OH}+\mathrm{N}_{2}$ & $1.080 \mathrm{E}+11$ & 0.50 & $-1.242 \mathrm{E}+03$ & {$[72]$} \\
36 & $\mathrm{OH}^{\star}+\mathrm{Ar}=\mathrm{OH}+\mathrm{Ar}$ & $1.690 \mathrm{E}+12$ & 0.00 & $4.135 \mathrm{E}+03$ & {$[94]$} \\
37 & $\mathrm{OH}^{\star}+\mathrm{H}{ }_{2} \mathrm{O}=\mathrm{OH}+\mathrm{H}_{2} \mathrm{O}$ & $5.930 \mathrm{E}+12$ & 0.50 & $-8.610 \mathrm{E}+02$ & {$[72]$} \\
38 & $\mathrm{OH}^{\star}+\mathrm{CO}=\mathrm{OH}+\mathrm{CO} 2$ & $2.750 \mathrm{E}+12$ & 0.50 & $-9.680 \mathrm{E}+02$ & {$[72]$} \\
39 & $\mathrm{OH}^{\star}+\mathrm{CO}=\mathrm{OH}+\mathrm{CO}$ & $3.230 \mathrm{E}+12$ & 0.50 & $-7.870 \mathrm{E}+02$ & {$[72]$} \\
40 & $\mathrm{OH}^{\star}+\mathrm{OH}=\mathrm{OH}+\mathrm{OH}$ & $6.010 \mathrm{E}+12$ & 0.50 & $-7.640 \mathrm{E}+02$ & {$[72]$} \\
41 & $\mathrm{OH}^{\star}=\mathrm{OH}+\mathrm{hv}$ & $1.450 \mathrm{E}+06$ & 0.00 & 0.0 & {$[95]$} \\
\hline
\end{tabular}


Table 3: Mixture composition for the ignition delay times experiments in the RCM from NUI Galway. (These data are new for this paper)

\begin{tabular}{cccccc}
\hline $\mathrm{H}_{2}(\%)$ & $\mathrm{CO}(\%)$ & $\mathrm{O}_{2}(\%)$ & $\mathrm{N}_{2}(\%)$ & $\mathrm{Ar}(\%)$ & $T_{c}(\mathrm{~K})$ \\
\hline 17.36 & 0.00 & 17.36 & 32.64 & 32.64 & $929-1014$ \\
14.76 & 2.60 & 17.36 & 32.64 & 32.64 & $940-1032$ \\
8.68 & 8.68 & 17.36 & 32.64 & 32.64 & $932-1022$ \\
4.34 & 13.02 & 17.36 & 32.64 & 32.64 & $963-1049$ \\
\hline
\end{tabular}


Table 4: Mixture composition for the ignition delay times experiments in the RCM from the University of Connecticut. (These data are new for this paper)

\begin{tabular}{ccccc}
\hline $\mathrm{H}_{2}(\%)$ & $\mathrm{CO}(\%)$ & $\mathrm{O}_{2}(\%)$ & $\mathrm{N}_{2}(\%)$ & $T_{c}(\mathrm{~K})$ \\
\hline 12.500 & 0.000 & 6.250 & 81.250 & $914-1010$ \\
6.250 & 6.250 & 6.250 & 81.250 & $929-1031$ \\
3.125 & 9.375 & 6.250 & 81.250 & $959-1052$ \\
1.250 & 11.250 & 6.250 & 81.250 & $973-1068$ \\
\hline
\end{tabular}


Table 5: Experimental conditions for the shock-tube study of various $\mathrm{H}_{2} / \mathrm{O}_{2}$ mixtures diluted in $98 \%$ Ar at TAMU. (These data are new for this paper).

\begin{tabular}{ccccc}
\hline$\phi$ & $\begin{array}{c}\mathrm{H}_{2} \\
(\text { mol. \%) }\end{array}$ & $\begin{array}{c}\mathrm{O}_{2} \\
(\text { mol. \%) }\end{array}$ & $\begin{array}{c}T_{5} \\
(\mathrm{~K})\end{array}$ & $\begin{array}{c}p_{5} \\
\text { (atm) }\end{array}$ \\
\hline \multirow{2}{*}{0.3} & & & $975-1530$ & $1.67 \pm 0.12$ \\
& \multirow{2}{*}{0.75} & \multirow{2}{*}{1.25} & $1090-1250$ & $14.4 \pm 1.9$ \\
& & & $1155-1230$ & $32.8 \pm 1.4$ \\
\hline \multirow{2}{*}{0.5} & \multirow{2}{*}{1.0} & & $960-1625$ & $1.65 \pm 0.15$ \\
& & & $1085-1245$ & $13.3 \pm 1.0$ \\
& & & $1160-1270$ & $32.8 \pm 1.5$ \\
\hline \multirow{2}{*}{1.0} & \multirow{2}{*}{1.33} & & $1035-1740$ & $1.66 \pm 0.23$ \\
& & & $1105-1210$ & $14.0 \pm 1.3$ \\
& & & $1140-1260$ & $33.8 \pm 0.9$ \\
\hline
\end{tabular}


Table 6: Experimental conditions for the shock-tube experiments at DLR. (These data are new for this paper)

\begin{tabular}{ccccccccc}
\hline $\begin{array}{c}\text { Fuel } \\
\left(\mathrm{H}_{2} / \mathrm{CO}\right)(\%)\end{array}$ & $\phi$ & $\begin{array}{c}\mathrm{H}_{2} \\
(\mathrm{~mol} . \%)\end{array}$ & $\begin{array}{c}\mathrm{CO} \\
(\mathrm{mol} . \%)\end{array}$ & $\begin{array}{c}\mathrm{O}_{2} \\
(\mathrm{~mol} . \%)\end{array}$ & $\begin{array}{c}\mathrm{N}_{2} \\
(\mathrm{~mol} . \%)\end{array}$ & $\begin{array}{c}\mathrm{Ar} \\
(\mathrm{mol} . \%)\end{array}$ & $\begin{array}{c}T_{5} \\
(\mathrm{~K})\end{array}$ & $\begin{array}{c}p_{5} \\
(\mathrm{~atm})\end{array}$ \\
\hline \multirow{2}{*}{$100 / 0$} & 0.1 & 0.81 & & 4.03 & & 95.16 & $925-2100$ & $1,4,16$ \\
& 0.5 & 3.47 & & 3.47 & 93.06 & & $950-2000$ & $1,4,16$ \\
& 4.0 & 12.54 & & 1.57 & & 85.89 & $935-1850$ & $1,4,16$ \\
\hline $85 / 15$ & 0.5 & 2.98 & 0.52 & 3.51 & 46.57 & 46.42 & $1020-1220$ & 16 \\
\hline \multirow{2}{*}{$50 / 50$} & 0.5 & 1.74 & 1.74 & 3.47 & & 93.06 & $870-2100$ & $1,4,16$ \\
& 0.5 & 1.74 & 1.74 & 3.52 & 47.32 & 45.68 & $1000-1220$ & 16 \\
& 1.0 & 2.96 & 2.96 & 2.96 & & 91.12 & $910-2170$ & $1,4,16$ \\
\hline $5 / 95$ & 0.5 & 0.17 & 3.30 & 3.47 & & 93.06 & $940-2220$ & $1,4,16$ \\
& 1.0 & 0.30 & 5.62 & 2.96 & & 91.12 & $950-2200$ & $1,4,16$ \\
\hline
\end{tabular}




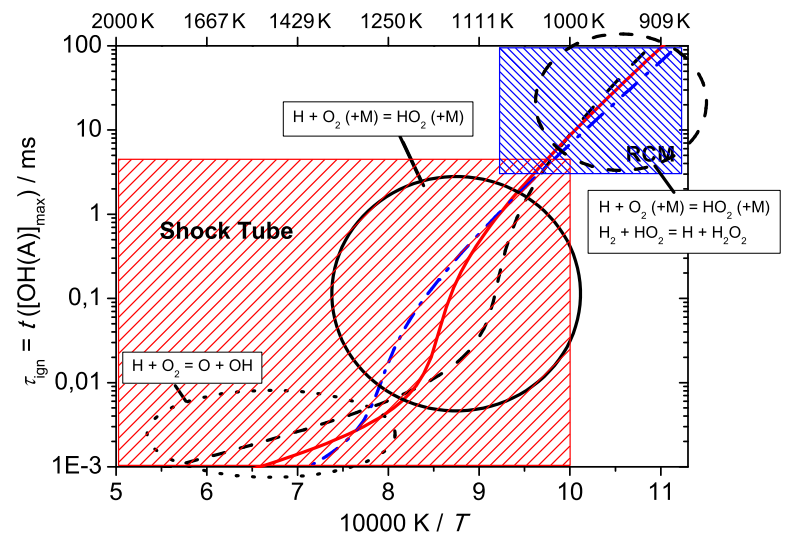

Figure 1: Main reactions as function of the temperature regime for a mixture of $0.7 \mathrm{H}_{2}+$ $\mathrm{O}_{2}+3.76$ Ar tested with the present mechanism at 8 bar (- - -), 16 bar ( -) and 32 bar $(-\cdot-)$. 


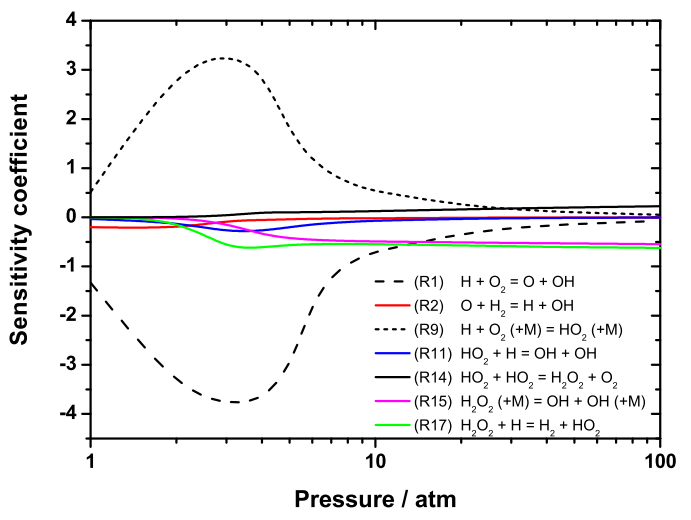

Figure 2: Sensitivity analysis of ignition time delays as a function of pressure at $1000 \mathrm{~K}$ for the present mechanism (Mixture: $\mathrm{H}_{2} / \mathrm{O}_{2} / \mathrm{N}_{2} / \mathrm{Ar}=1 / 1 / 1.88 / 1.88$ ) - Only the top 7 most sensitive reactions are included for clarity. 


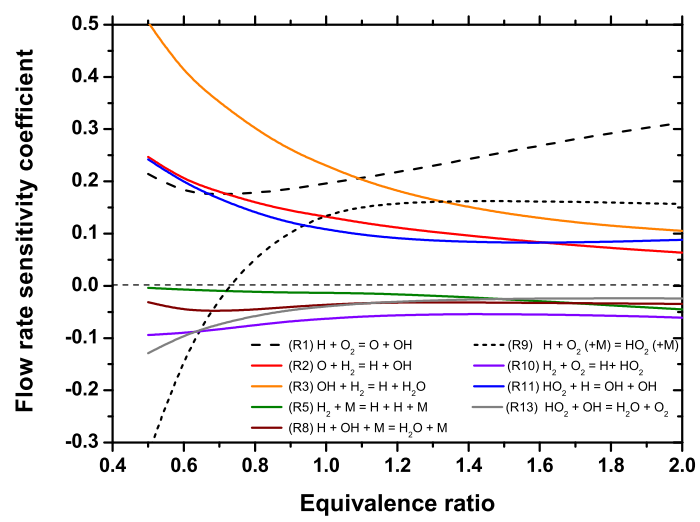

Figure 3: Flow rate sensitivity analysis of laminar flame speed of hydrogen in air at 298 $\mathrm{K}$ and $1 \mathrm{~atm}$ as a function of equivalence ratio for the present mechanism - Only the top 9 most sensitive reactions are included for clarity. 


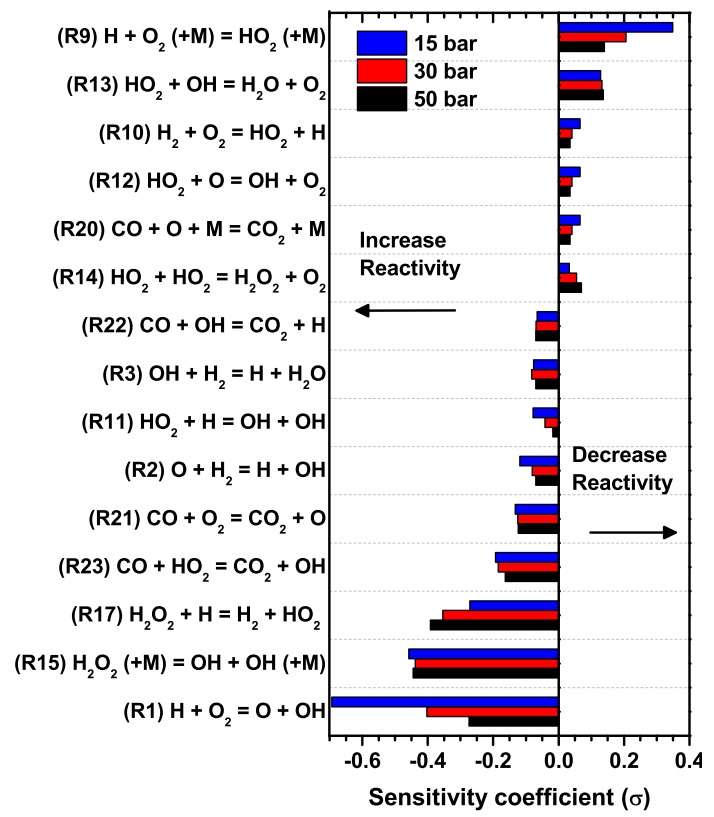

Figure 4: The top 15 most sensitive reactions at $1000 \mathrm{~K}$ and pressures of 15,30 and 50 bar (Mixture: $\mathrm{H}_{2} / \mathrm{CO} / \mathrm{O}_{2} / \mathrm{N}_{2} / \mathrm{Ar}=2.5 / 10 / 6.25 / 18.125 / 63.125$ ). 


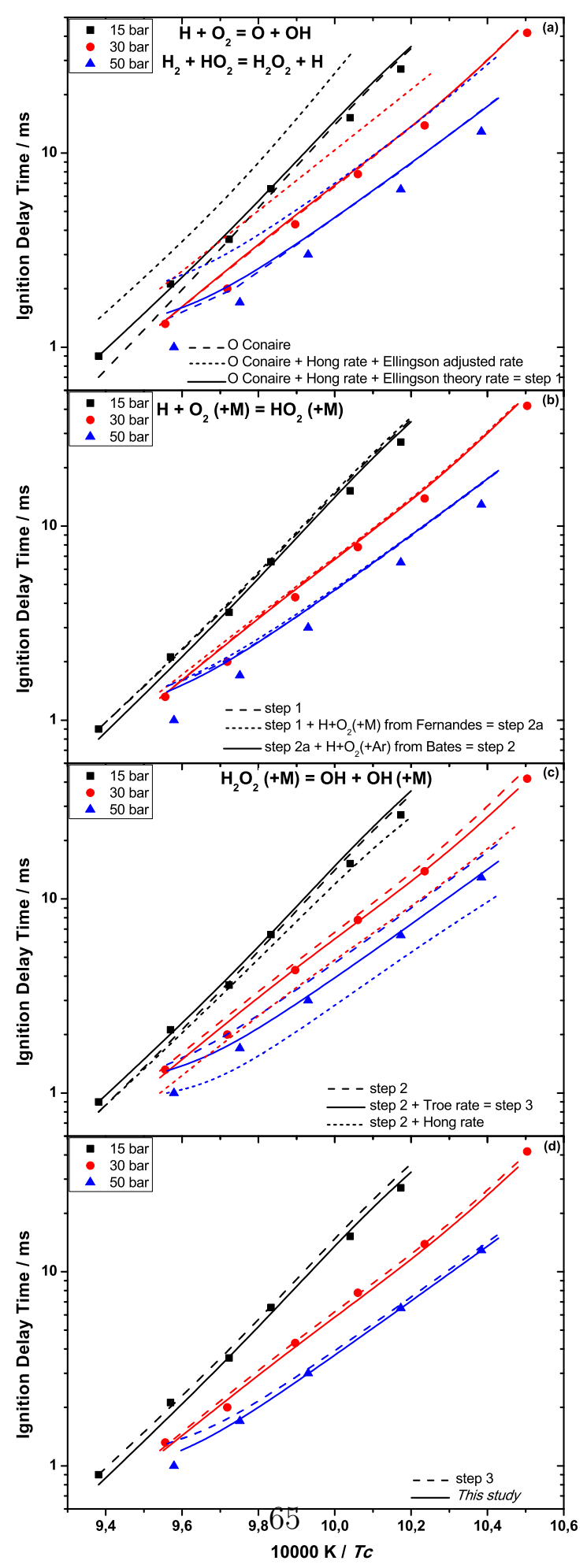

Figure 5: Main steps for the kinetic mechanism improvement (Experimental results : Mittal et al. [13]). 


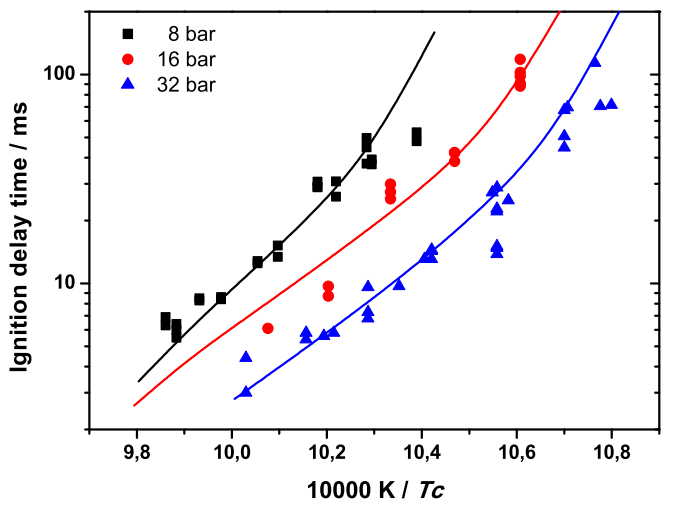

Figure 6: Effect of pressure on ignition delay times of hydrogen measured in a RCM in NUI Galway $\left(17.36 \% \mathrm{H}_{2}+17.36 \% \mathrm{O}_{2}+32.64 \% \mathrm{~N}_{2}+32.64 \% \mathrm{Ar}\right)$. 


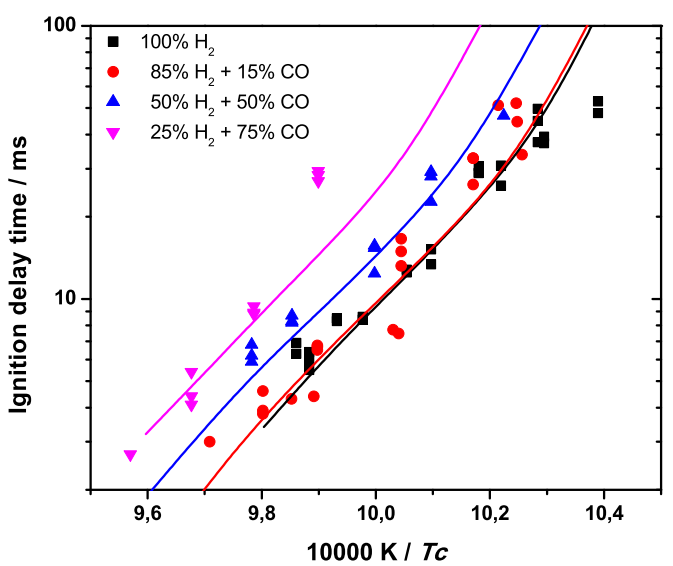

Figure 7: Effect of $\mathrm{CO}$ concentration on ignition delay times of syngas mixtures measured in a RCM in NUI Galway $\left(\mathrm{P}_{c}=8\right.$ bar $-17.36 \%\left(\alpha \mathrm{H}_{2}+(1-\alpha) \mathrm{CO}\right)+17.36 \% \mathrm{O}_{2}+32.64 \%$ $\mathrm{N}_{2}+32.64 \%$ Ar). 


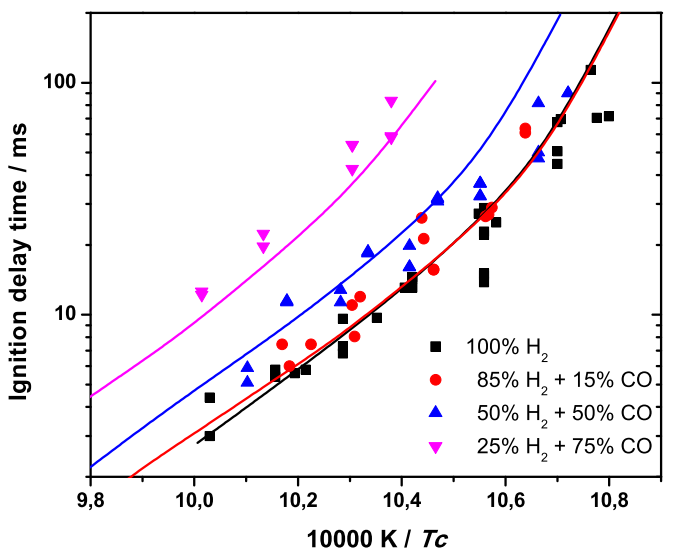

Figure 8: Effect of $\mathrm{CO}$ concentration on ignition delay times of syngas mixtures measured in a RCM in NUI Galway $\left(\mathrm{P}_{c}=32\right.$ bar $-17.36 \%\left(\alpha \mathrm{H}_{2}+(1-\alpha) \mathrm{CO}\right)+17.36 \% \mathrm{O}_{2}+32.64 \%$ $\mathrm{N}_{2}+32.64 \%$ Ar). 


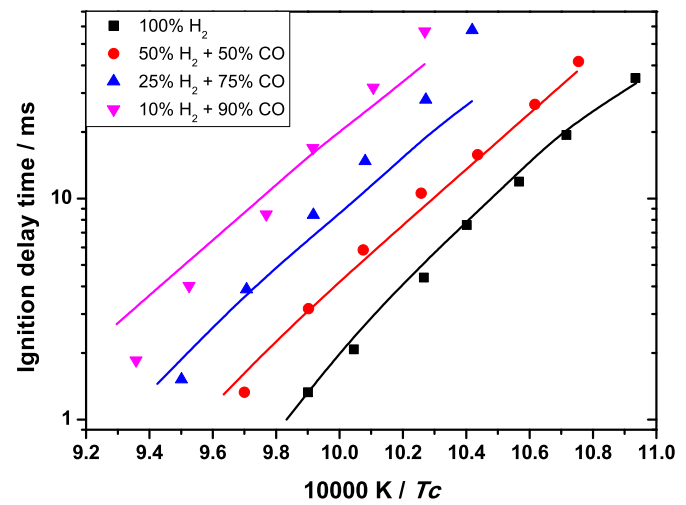

Figure 9: Effect of $\mathrm{CO}$ concentration on ignition delay times measured in a RCM in the University of Connecticut $\left(\mathrm{P}_{c}=70 \mathrm{bar}-12.5 \%\left(\alpha \mathrm{H}_{2}+(1-\alpha) \mathrm{CO}\right)+6.25 \% \mathrm{O}_{2}+81.25 \% \mathrm{~N}_{2}\right)$. 


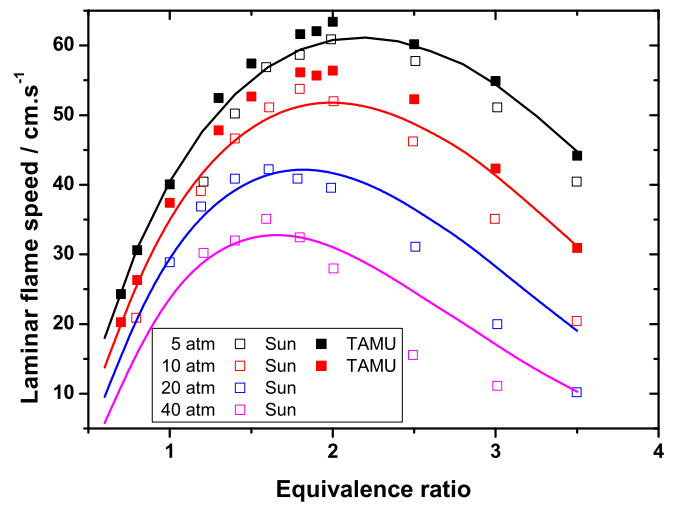

Figure 10: Comparison with flame speed measurements from Sun et al. and [60] and this study (from TAMU) $\left(95 \% \mathrm{CO}+5 \% \mathrm{H}_{2}\right.$ in $\left.\mathrm{O}_{2}+7 \mathrm{He}-\mathrm{T}_{i}=298 \mathrm{~K}\right)$. 


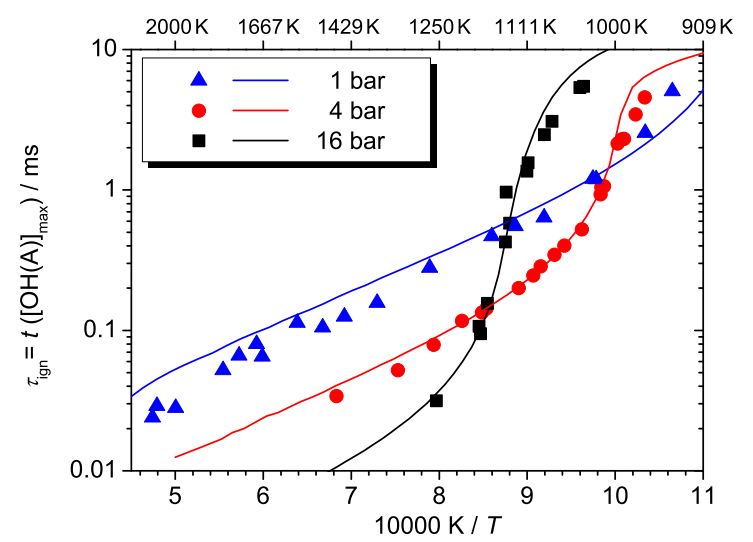

Figure 11: Measured and calculated ignition delay times of a $\mathrm{H}_{2} / \mathrm{O}_{2} / \mathrm{Ar}$ mixture at an equivalence ratio $\phi=0.1$ and a dilution of 1:5. Experiments were performed in a shock-tube at DLR. (see Table 6 for mixture composition). 


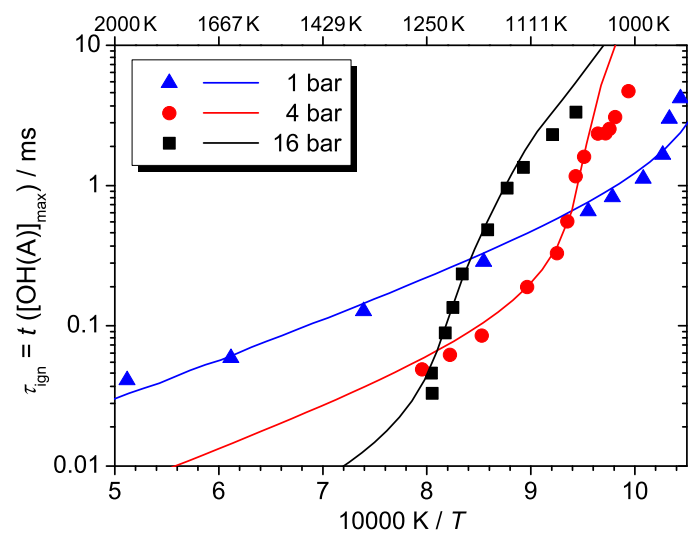

Figure 12: Measured and calculated ignition delay times of a $\mathrm{H}_{2} / \mathrm{O}_{2} / \mathrm{N}_{2}$ mixture at an equivalence ratio $\phi=0.5$ and a dilution of 1:5. Experiments were performed in a shock-tube at DLR. (see Table 6 for mixture composition). 


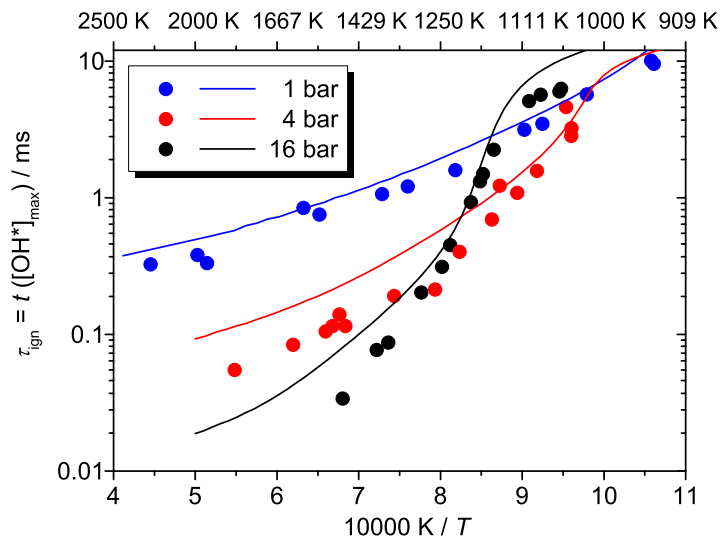

Figure 13: Measured and calculated ignition delay times of a syngas $\left(5 \% \mathrm{H}_{2} / 95 \% \mathrm{CO}\right) /$ $\mathrm{O}_{2} / \mathrm{Ar}$ mixture at an equivalence ratio $\phi=0.5$ and a dilution of 1:5. Experiments were performed in a shock-tube at DLR. (see Table 6 for mixture composition). 


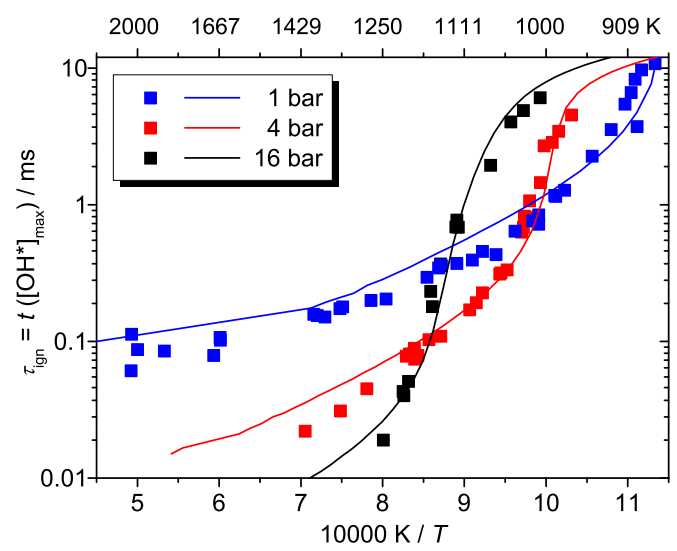

Figure 14: Measured and calculated ignition delay times of a syngas $\left(50 \% \mathrm{H}_{2} / 50 \% \mathrm{CO}\right)$ $/ \mathrm{O}_{2} / \mathrm{Ar}$ mixture at an equivalence ratio $\phi=0.5$ and a dilution of 1:5. Experiments were performed in a shock-tube at DLR. (see Table 6 for mixture composition). 


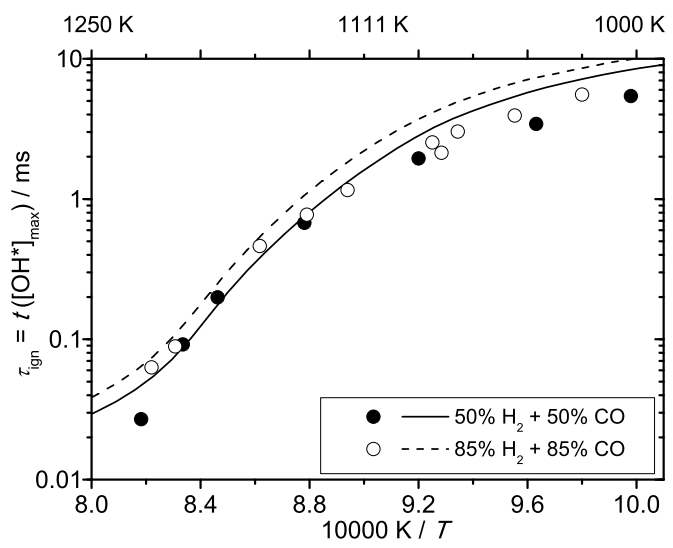

Figure 15: Measured (symbols) and calculated (lines) ignition delay times of two syngas mixtures $\left(85 \% \mathrm{H}_{2} / 15 \% \mathrm{CO}\right.$ and $\left.50 \% \mathrm{H}_{2} / 50 \% \mathrm{CO}\right) / \mathrm{O}_{2} /$ inert gas $(50 \% \mathrm{Ar} / 50 \%$ $\mathrm{N}_{2}$ ) mixture at an equivalence ratio $\phi=0.5$, a dilution of $1: 5$ and a pressure $p=16$ bar. Experiments were performed in a shock-tube at DLR. (see Table 6 for mixture composition). 


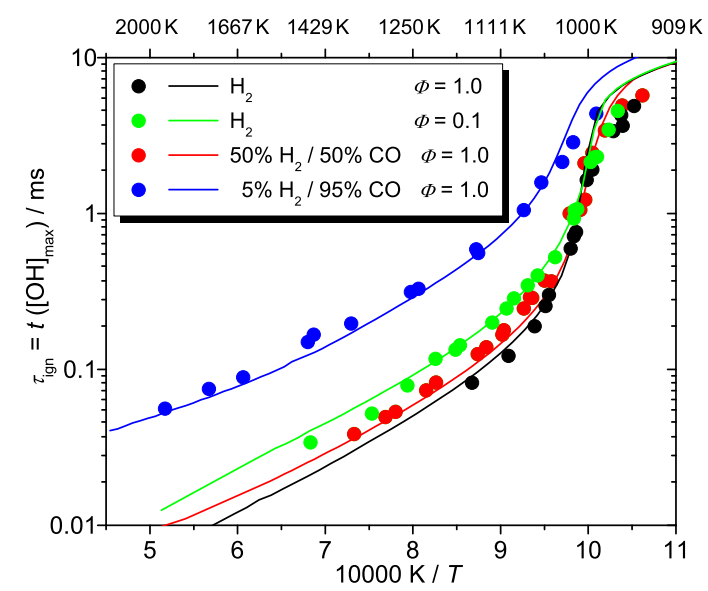

Figure 16: Measured and calculated ignition delay times of $\mathrm{H}_{2}$ and syngas / $\mathrm{O}_{2} / \mathrm{Ar}$ mixtures at a dilution of $1: 5$ and a pressure $p=4$ bar. 


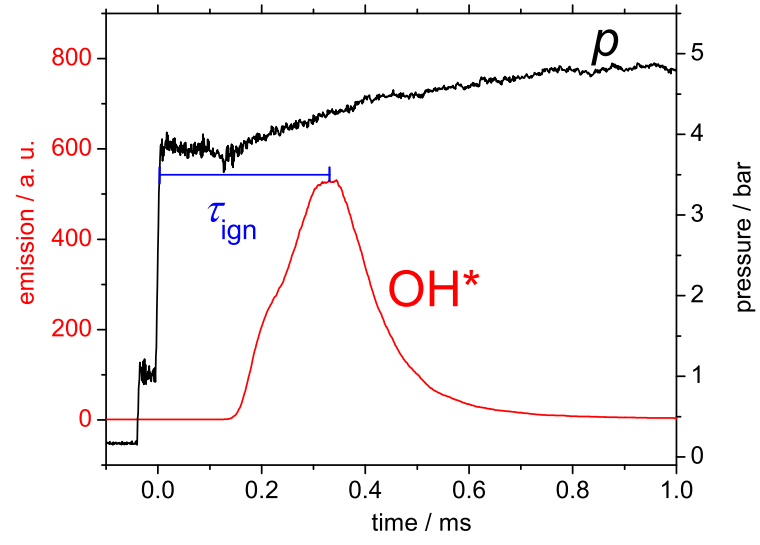

Figure 17: Pressure and emission signal of a $\left(5 \% \mathrm{H}_{2} / 95 \% \mathrm{CO}\right) / \mathrm{O}_{2} / \mathrm{Ar}$ mixture $(\phi=$ 1.0, dilution 1:5) at $p_{5}=3.79$ bar and $T_{5}=1240 \mathrm{~K}$. 


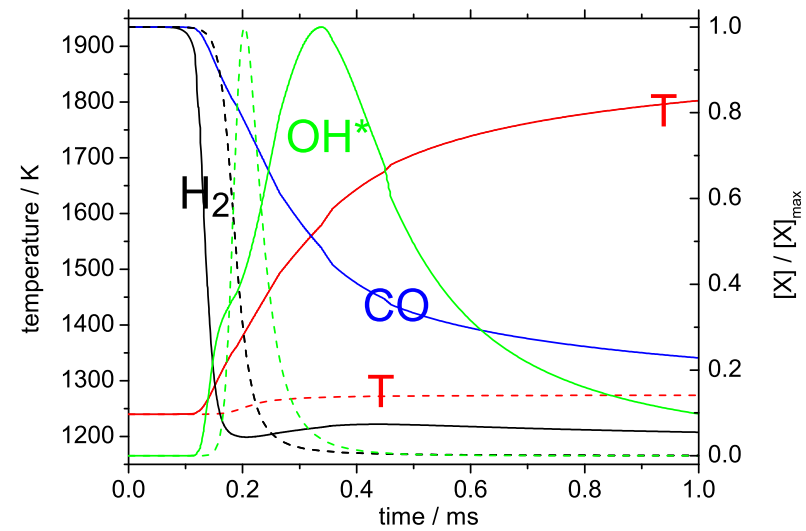

Figure 18: Calculated temperatures and concentrations of a $\left(5 \% \mathrm{H}_{2} / 95 \% \mathrm{CO}\right) / \mathrm{O}_{2} / \mathrm{Ar}$ mixture $\left(\phi=1.0\right.$, dilution 1:5) and a $\mathrm{H}_{2} / \mathrm{O}_{2} /$ Ar mixture $(\phi=0.05, \mathrm{CO}$ of the syngas mixture replaced by Ar) at $p=3.79$ bar and $T=1240 \mathrm{~K}$. Black lines: $\mathrm{H}_{2}$, green lines: $\dot{\mathrm{O}} \mathrm{H}^{\star}$, blue line: $\mathrm{CO}$, red lines: temperatures. Full lines: $5 \% \mathrm{H}_{2} / 95 \% \mathrm{CO}$, dashed lines: $\mathrm{H}_{2}$. 


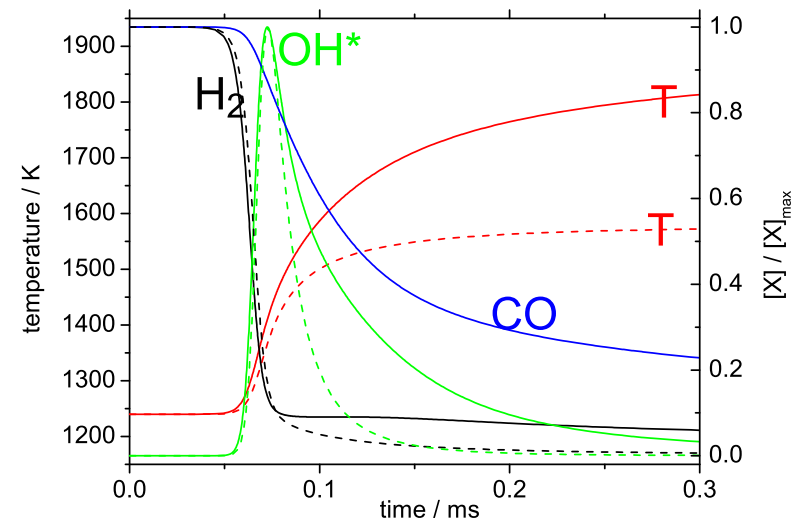

Figure 19: Calculated temperatures and concentrations of a $\left(50 \% \mathrm{H}_{2} / 50 \% \mathrm{CO}\right) / \mathrm{O}_{2} /$ Ar mixture $\left(\phi=1.0\right.$, dilution 1:5) and a $\mathrm{H}_{2} / \mathrm{O}_{2} /$ Ar mixture $(\phi=0.5$, CO of the syngas mixture replaced by Ar) at $p=3.79$ bar and $T=1240 \mathrm{~K}$. Black lines: $\mathrm{H}_{2}$, green lines: $\dot{\mathrm{O}} \mathrm{H}^{\star}$, blue line: $\mathrm{CO}$, red lines: temperatures. Full lines: $50 \% \mathrm{H}_{2} / 50 \% \mathrm{CO}$, dashed lines: $\mathrm{H}_{2}$. 


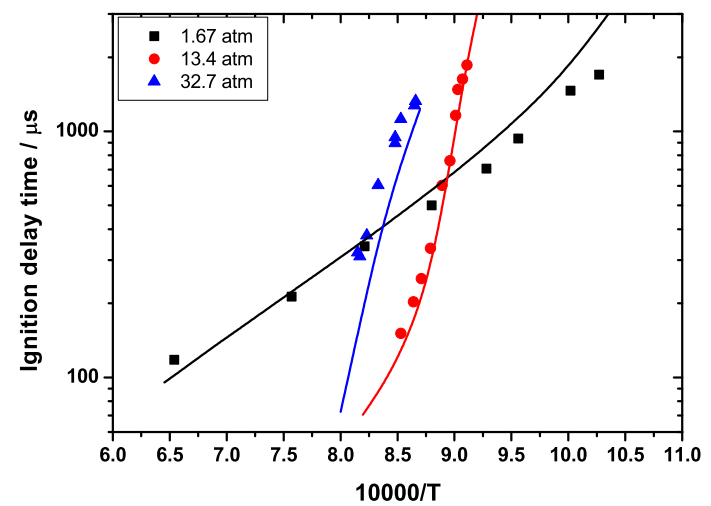

Figure 20: Ignition delay times of $\mathrm{H}_{2} / \mathrm{O}_{2} / \mathrm{Ar}$ mixtures $(\phi=0.3)$ measured in TAMU shock tube. 


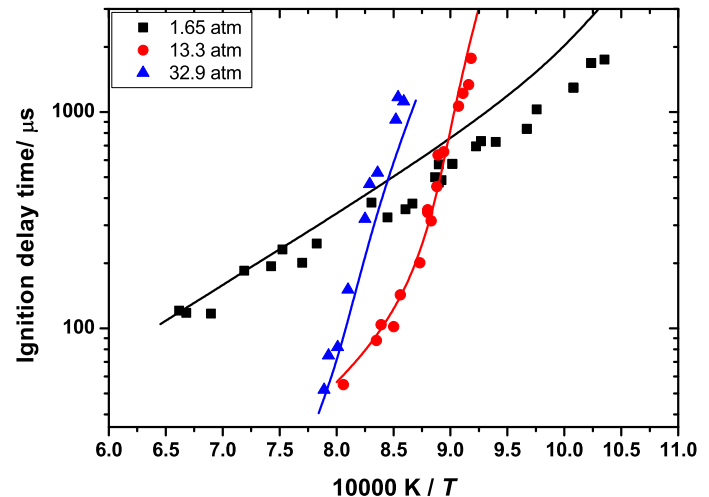

Figure 21: Ignition delay times of $\mathrm{H}_{2} / \mathrm{O}_{2} / \mathrm{Ar}$ mixtures $(\phi=0.5)$ measured in TAMU shock tube. 


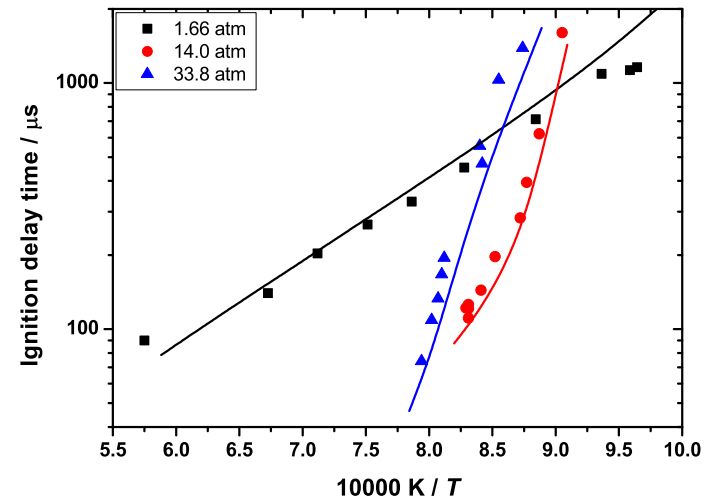

Figure 22: Ignition delay times of $\mathrm{H}_{2} / \mathrm{O}_{2} / \mathrm{Ar}$ mixtures $(\phi=1.0)$ measured in TAMU shock tube. 